\title{
PASSEIO PÚBLICO DE CONCRETO PERMEÁVEL DE CIMENTO PORTLAND COMO ELEMENTO DE DRENAGEM DE ÁGUAS PLUVIAIS
}

\author{
PUBLIC FOOTPATH IN PERMEABLE CONCRETE OF PORTLAND CEMENT AS AN \\ ELEMENT OF RAINWATER DRAINAGE
}

\author{
Rafael Staparo Vale ${ }^{1}$ \\ Jorge Herculano de Oliveira ${ }^{2}$ \\ Daniel Hesselbarth Valcarce ${ }^{3}$ \\ Guilherme Vinicius da Silva Borba ${ }^{4}$ \\ Vinícius Luiz da Jesus Miranda ${ }^{5}$ \\ Valdeir Vinícius da Silva Duarte 6 \\ Leonardo Moraes Armesto ${ }^{7}$
}

RESUMO: O concreto permeável de cimento Portland é um material desenvolvido para aumentar a permeabilidade do pavimento através de uma superfície porosa que beneficia a drenagem urbana. Além disso, ambientalmente falando, reduz o escoamento superficial, permitindo a filtragem da poluição ocasionada por óleos, fluídos de automóveis e demais substâncias encontradas na pavimentação urbana. Nesse contexto, o concreto permeável é uma alternativa aos problemas de drenagem urbana, cujos benefícios vão além dos econômicas e ambientais; uma drenagem eficiente pode evitar perdas humanas e materiais decorrentes das enchentes e inundações. Este trabalho objetiva avaliar a viabilidade e a confiabilidade deste tipo de pavimento, apresentando as vantagens e facilidades de seu uso, assim como suas limitações, a partir da determinação da sua capacidade de permeabilidade e resistência mecânica. Para tanto, uma metodologia de ensaio laboratorial faz-se necessária, além do estudo de intensidade pluviométrica de uma região em estudo. A pesquisa é baseada em revistas cientificas e artigos que, através de estudos de caso e outras literaturas relacionadas, trouxeram resultados significativos sobre o uso do concreto permeável como

\footnotetext{
${ }^{I}$ Graduando em Engenharia Civil pela Universidade Paulista. E-mail: rafaelstaparo34@yahoo.com.br.

${ }^{2}$ Graduando em Engenharia Civil pela Universidade Paulista. E-mail: jherculanodeoliveira@gmail.com.

3 Universidade Paulista. E-mail: daniel_hesselbarth@hotmail.com.

${ }^{4}$ Graduando em Engenharia Civil pela Universidade Paulista. E-mail:guilhermevsborba@gmail.com.

5 Graduando em Engenharia Civil pela Universidade Paulista. E-mail:viniciusmirandajesus@hotmail.com.

${ }^{6}$ Graduando em Engenharia Civil pela Universidade Paulista. E-mail:valdeirfc@outlook.com.

7 Doutorando Acadêmico em Engenharia de Materiais e Nanotecnologia, Mestrado em Bioengenharia pela UNIESP-Universidade Brasil, pós-Graduação em Gestão Estratégica de Negócios na instituição de ensino Centro Universitário Monte Serrat (Unimonte), Pós-Graduação "Extensão" em Energias Renováveis, pela Politécnica Universidad de Madrid e em Astrofísica pela Universidade de Santa Catarina. Especialista em Arquitetura, Construção e Gestão de Edificações Sustentáveis. Especialização em Filosofia e História da Ciência, Ensino: Astronomia. Graduado em Engenharia Civil na instituição Centro Universitário Monte Serrat, Engenharia Eletricidade e Engenharia Industrial Mecânica pelo Instituto Brasileiro de Tecnologia Avançada, Licenciatura em Física, Matemática e Filosofia, Licenciado em Química (Nível R2) e Licenciando em História pela Universidade de Franca e Cruzeiro do Sul, respectivamente; além de Medicina pela autarquia pública na Faculdade Municipal de São Caetano do Sul. Empresário, Palestrante, Assessor e Consultor em assuntos de planejamento estratégico.
} 
elemento de drenagem urbana e suas características. Os estudos desse tipo de concreto, em sua grande maioria, defendem seu uso como alternativa ao manejo correto de águas pluviais, apontando apenas sua limitação a cargas reduzidas em função da razão entre a resistência e a permeabilidade. $O$ uso do concreto permeável pode minimizar problemas ambientais decorrentes da impermeabilização do solo, possibilitando a infiltração de água para os aquíferos subterrâneos. Com esses resultados é possível perceber que o concreto permeável pode ser empregado como solução dos problemas de drenagem urbana existentes ou até considerado em projetos para novos empreendimentos, uma vez que, permeável, pode-se tornar útil uma parcela maior do terreno, construindo playgrounds, passeios e vagas descobertas, por exemplo, respeitando os limites mínimos de área permeável definidos por lei.

Palavras-chave: Concreto Permeável. Drenagem Urbana. Permeabilidade. Impermeabilização do solo. Pavimento permeável.

ABSTRACT: Portland cement pervious concrete is a material developed to increase the permeability pavement through a porous surface what benefits urban drainage. Besides that, environmentally speaking, it reduces the outflow of rainwater, allowing the filtering of pollution caused by oils, automobiles fluids and some other substances found in urban paving. In this context, pervious concrete is an alternative to solve problems of urban drainage, whose benefits go beyond economic and environmental. An efficient drainage can prevent both human and materials losses from flooding. This assignment aims to evaluate the feasibility and reliability of this type of pavement, presenting the advantages and facilities of its use, as well as its limitations, based on the determination of its permeability capacity and mechanical resistance. Therefore, a laboratory testing methodology is necessary, as well as a review of rainfall intensity of a region in study. The research is based in scientific journals and article that, through case studies and others related literatures, brought significative results about the use of pervious concrete as an element of urban drainage and its characteristics. Most studies of this type of concrete defend its use as an alternative to the correct management of the rainwater, pointing out only it's limitation to reduced loads due to the ratio between its resistance and permeability. The use of the pervious concrete can minimize enviromental problems arising from soil impermeability enabling water infiltration into underground aquifers. With these results it is possible to realize that the pervious concrete can be employed as a solution to the existing urban drainage problems or even considered in projects for new real state ventures as, once the soil is pervious, a larger portion of the land can become useful, by building playgrounds, sidewalks and uncovered parking lots, for example, respecting the minimum limits of area defined by law.

Keywords: Pervious concrete. Urban Drainage. Permeability. Soil Waterproofing. Permea ble pavement. 


\section{REVISÃO DA LITERATURA}

\section{I.I Definição segundo a NBR 16416:2015, vantagens e desvantagens do Concreto Permeável de Cimento Portland}

De acordo com a Associação Brasileira de Normas Técnicas (ABNT) Norma Brasileira (NBR) ı6416 (2015), Concreto Permeável de Cimento Portland (CPCP) é aquele cujos vazios interligados permitem a percolação de água por ação da gravidade. Ainda segundo a mesma norma, pavimento permeável é aquele capaz de resistir aos esforços mecânicos e às condições de rolamento, além de permitir a infiltração de água ou seu acúmulo temporário sem prejuízo para a estrutura.

De maneira semelhante, Lamb et al (2013) definem concreto permeável ou drenante como o material que apresenta índice de vazios, ou porosidade, entre 15 e $25 \%$ a fim de permitir a infiltração de águas pluviais. Em relação ao concreto convencional, observa-se a pequena quantidade de agregado miúdo, quando esta não é nula; conseguindo drenar, em média, $200 \ell / \mathrm{min} . / \mathrm{m}^{2}$, capacidade bem acima daquela apresentada pelos solos. Entretanto, para Pils et al (2019), o índice de vazios é um pouco maior, variando entre 18 e $35 \%$.

Dentre algumas vantagens, Xie et al (2019) citam a redução do efeito ilha de calor, a redução de ruídos causados pelo contato dos pneus automotivos, a minimização do efeito de aquaplanagem e a diminuição de sólidos suspensos nas águas pluviais, como nitrogênio e fósforo. Além disso, trata-se de um material que ajuda no controle dos impactos oriundos das mudanças feitas sobre o meio ambiente natural e que, comparado ao concreto convencional, tem baixo consumo de cimento, cuja produção emite gases do efeito estufa. Além disso, Becker et al (2019) citam a redução da quantidade de poluentes como metais pesados.

Chindaprasirt et al (2008) relatam que diversos estudos foram empreendidos com o intuito de conhecer as propriedades e características do CPCP, de forma que a alta permeabilidade desse composto é a sua propriedade mais atraente. Unissonante, Costa et al (2019) afirmam, ainda, que o CPCP ganhou notoriedade recentemente quando foi reconhecido pelo Conselho de Soluções Ecológicas dos EUA, responsável por classificar as construções sustentáveis através do sistema LEED (Leadership in Energy and Environmental Design). Segundo Zhong et al (2018), o interesse crescente por 
esse material é a razão pelo qual o número de pesquisas sobre ele cresceu nos primeiros anos do século XXI (figura I).

Figura I - Crescimento de pesquisas sobre CPCP realizadas no começo do século XXI

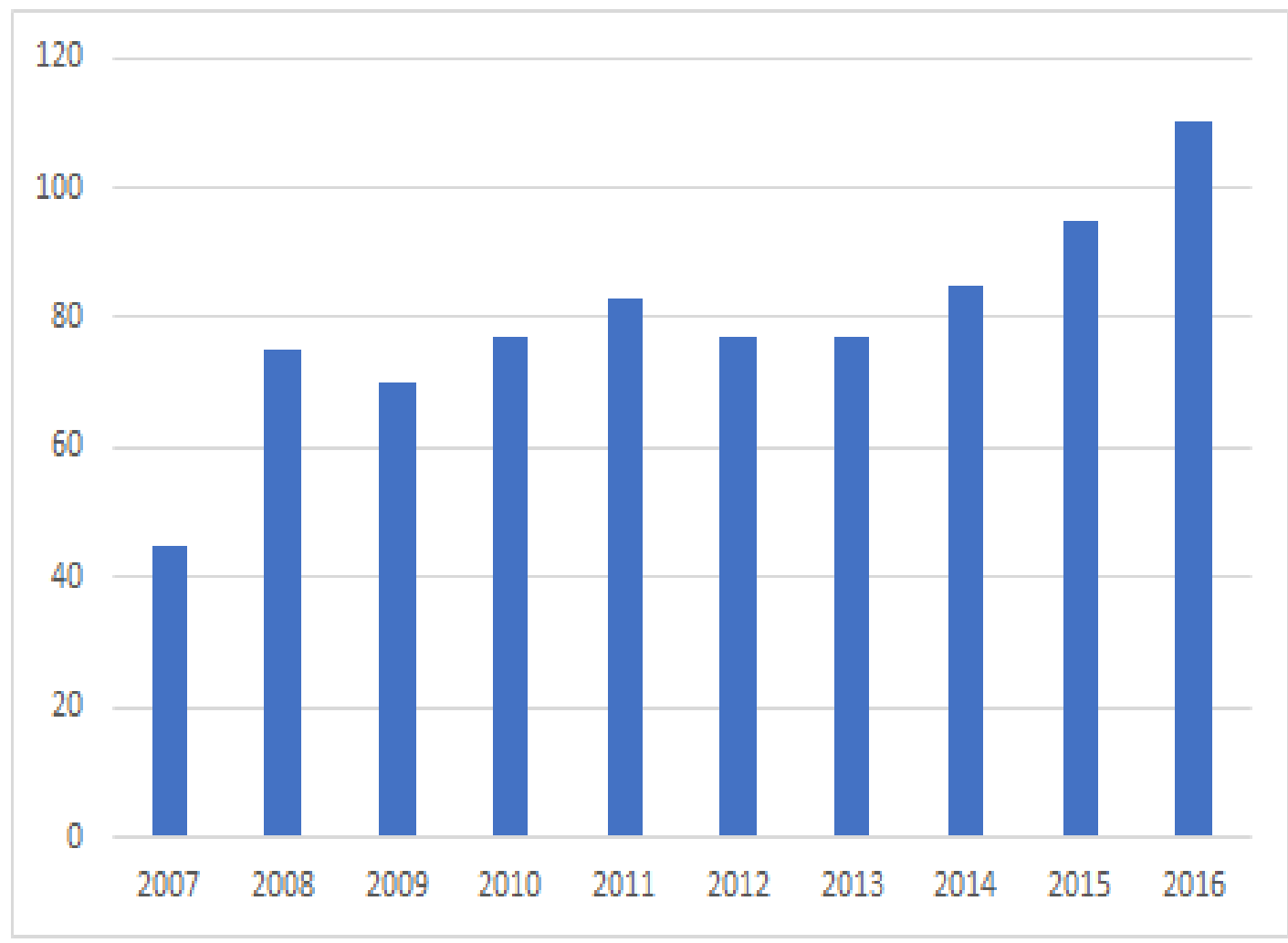

Fonte: Adaptado de Zhong et al (2018)

Porém, Sartipi et al(2019) alertam que esse material permite o crescimento de vegetação por entre os poros, de tal forma que é recomendada a aplicação de algum produto químico inibidor desse crescimento. Joshaghani et al (2015) apontam também uma desvantagem em relação ao concreto convencional: a resistência à compressão do CPCP é menor, isso deve-se em função da alta porosidade desse material, via de regra entre 15 e $25 \%$.

O Projeto Técnico: Pavimento Permeável da Associação Brasileira de Cimento Portland (ABCP) (2013) alerta também que o CPCP não impede que as águas pluviais contaminem o lençol freático, além de estarem sujeitos à colmatação, isto é, o acúmulo de sedimentos nas camadas inferiores do pavimento, o que causa a perda da permeabilidade. 


\subsubsection{Aplicação de pedrisco e aditivos na mistura do Concreto Permeável de Cimento Portland}

De acordo com Lamb et al (2013), o American Concrete Institute (ACI) recomenda o uso de pedrisco, ou brita zero, por ser essa a faixa granulométrica mais adequada para o CPCP: 9,50 mm é o seu diâmetro máximo e 4,80 o módulo de finura. Corroborando com tal recomendação, muitos autores em suas pesquisas utilizaram a brita zero como agregado graúdo na mistura do CPCP (figura 2).

Figura 2 - Pedrisco de basalto

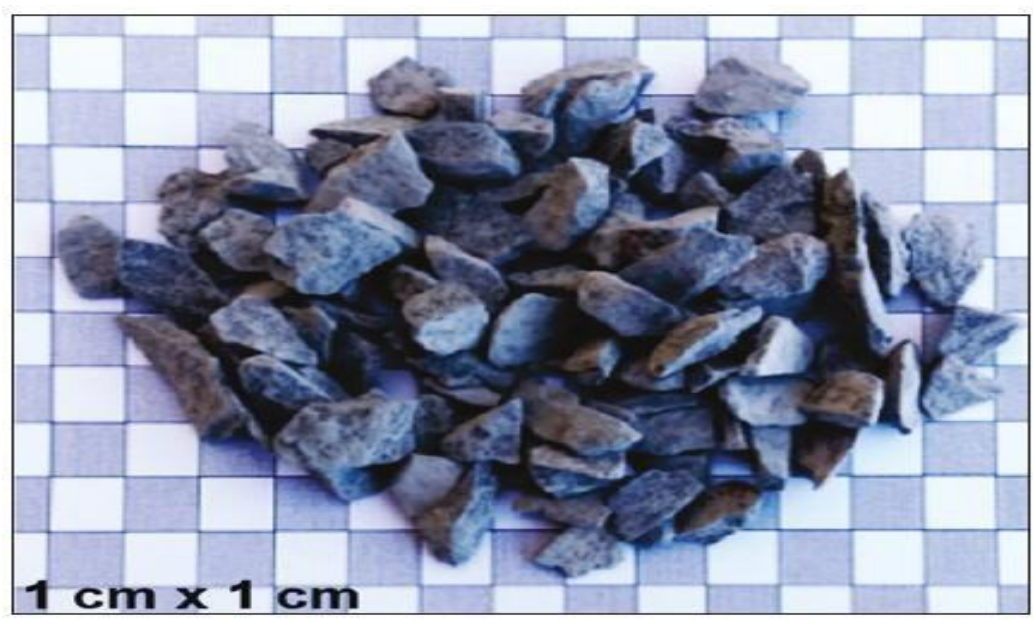

Fonte: Martins Filho et al (2020)

Para Martins Filho et al (2020), o diâmetro dos agregados deve ser uniforme, por se tratar de uma característica extremamente importante que definirá as propriedades do material. Para Xie et al (2019), os cuidados na dosagem desse tipo de concreto devem ser maiores e mais rigorosos.

De acordo com Lund et al (2017), outra possibilidade é a adição de aditivos que modificam as propriedades do material, seja no estado fresco, seja no endurecido. Aditivos retardadores de pega são comumente utilizados na fabricação de concreto permeável, já que a pasta de cimento tem pega mais rápida quando comparada à argamassa de cimento e areia do concreto convencional. Além disso, Soto-Pérez et al (2016) explicam que o uso de aditivos redutores de água contribui para as propriedades mecânicas do CPCP, uma vez que a razão ou fator água/cimento (a/c) é diminuída. 
De fato, estudos afirmam que com o uso de aditivos é possível aumentar a resistência mecânica do CPCP, visto que é uma deficiência nesse material. Yang et al (2003) afirmam que se pode obter uma resistência de compressão e tração de até so MPa e 6,o $\mathrm{MPa}$, respectivamente, adicionando dois tipos aditivos na mistura: Sílica ativa (SF) e Superplastificante (SP).

\subsubsection{Estudos sobre razão água/cimento e proporção dos materiais básicos do Concreto Permeável de Cimento Portland}

Schwetz et al (2015) afirmam que o CPCP é composto basicamente por pasta de cimento (cimento Portland + água) e agregado graúdo, com o intuito de se obter um material poroso. A quantidade de agregado miúdo é, na maioria das vezes, nula para que uma camada de pasta de cimento possa envolver os grãos de brita, formando os poros que garantirão a capacidade de infiltração, enquanto a razão a/c deve estar compreendida entre o,26 e o,45.

Já Elango et al (2020) sugerem que o fator a/c seja de 0,26 a o,40 e que o teor de cimento esteja entre 350 e $400 \mathrm{~kg} / \mathrm{m}^{3}$ para se atingir propriedades satisfatórias. O baixo fator a/c é responsável pela aparência de mistura seca e, consequentemente, pela baixa consistência desse material, que é entendida como a capacidade de fluidez do concreto, sendo verificada pelo ensaio de abatimento pelo tronco de cone ou slump test, cuja execução é especificada pela ABNT NBR i6889 (2020). No caso de CPCP, o slump é quase nulo, como representado na figura 3.

Figura 3 - Representação gráfico do ensaio de abatimento por tronco de cone

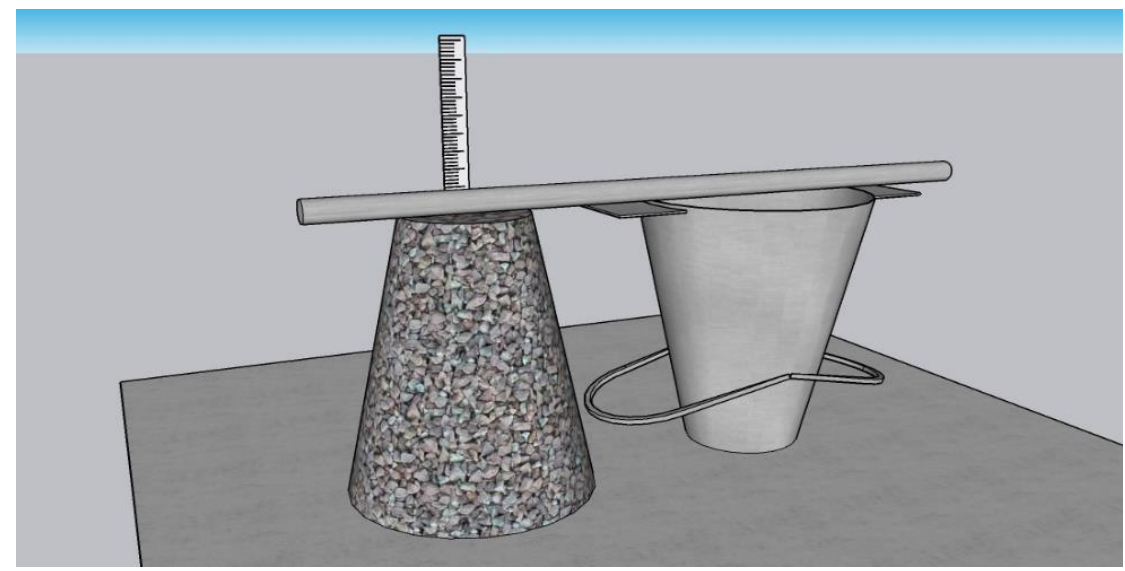

Fonte: Adaptado de Pils et al (2019) 
No entanto, Lian et al (2010) recomendam um fator a/c ideal entre 0,32 e 0,34. Tibbetts et al (2020) afirmam que essa razão afeta diretamente a permeabilidade do CPCP, ao passo que para Chindaprasirt et al (2008), a pasta de cimento deve ser altamente viscosa para garantir o envolvimento com a brita além de recomendarem o uso de Cimento Portland Comum (CP I).

Os estudos de Schwetz et al (2015) chegaram à conclusão de que pavimentos drenantes executados com fator a/c de o,30, pedrisco como agregado graúdo e traço i:3 (cimento: agregado graúdo) devem ser descartados em função da baixíssima permeabilidade, ao passo que os traços I:4 e i:5 mostraram-se satisfatórios apresentando boa capacidade de drenagem e resistência à compressão entre 4 e $5 \mathrm{MPa}$. Para Xie et al (2020), o traço do CPCP influencia diretamente nas suas propriedades.

Huang et al (2010) apresentam pesquisas onde foi adicionado agregado miúdo ao traço com intuito de se obter um acréscimo na resistência do CPCP: substituindo $7 \%$ em peso do agregado graúdo por areia de rio, ficou constatado o aumento de 9,60 para $14,50 \mathrm{MPa}$ já no $7^{\circ}$ dia de idade, isso sem comprometer a porosidade que ficou acima dos $15 \%$ considerados um valor mínimo.

\subsubsection{Recomendações da ABCP para lançamento e acomodação (adensamento) do Concreto Permeável de Cimento Portland moldado in loco (no local)}

De acordo com Parra et al (2015), antes do lançamento do CPCP, é necessário compactar adequadamente o subleito, para que este possa absorver os esforços gerados. Recomenda-se também que seja aplicada uma camada de material granular para servir de base e evitar a colmatação, isto é, o acúmulo de partículas sólidas no fundo do reservatório de brita.

Araújo et al (2000) também recordam a necessidade de se dimensionar sob o pavimento um reservatório para as águas pluviais e, sobre esse, um filtro. Ambos constituídos de material granular, porém, o reservatório com maior granulometria, recomendada por esses autores a faixa compreendida pela brita 3, cujo diâmetro varia de 25 a $50 \mathrm{~mm}$.

Além disso, a ABCP (2013) afirma que se pode optar pela instalação de uma manta geotêxtil (figura 4) sob a camada de agregado graúdo para que esta sirva como um 
filtro, impedindo que grãos de terra ou mesmo de pedra obstruam o tubo de dreno, que também pode ser instalado sob o pavimento.

Figura 4 - Assentamento da manta geotêxtil

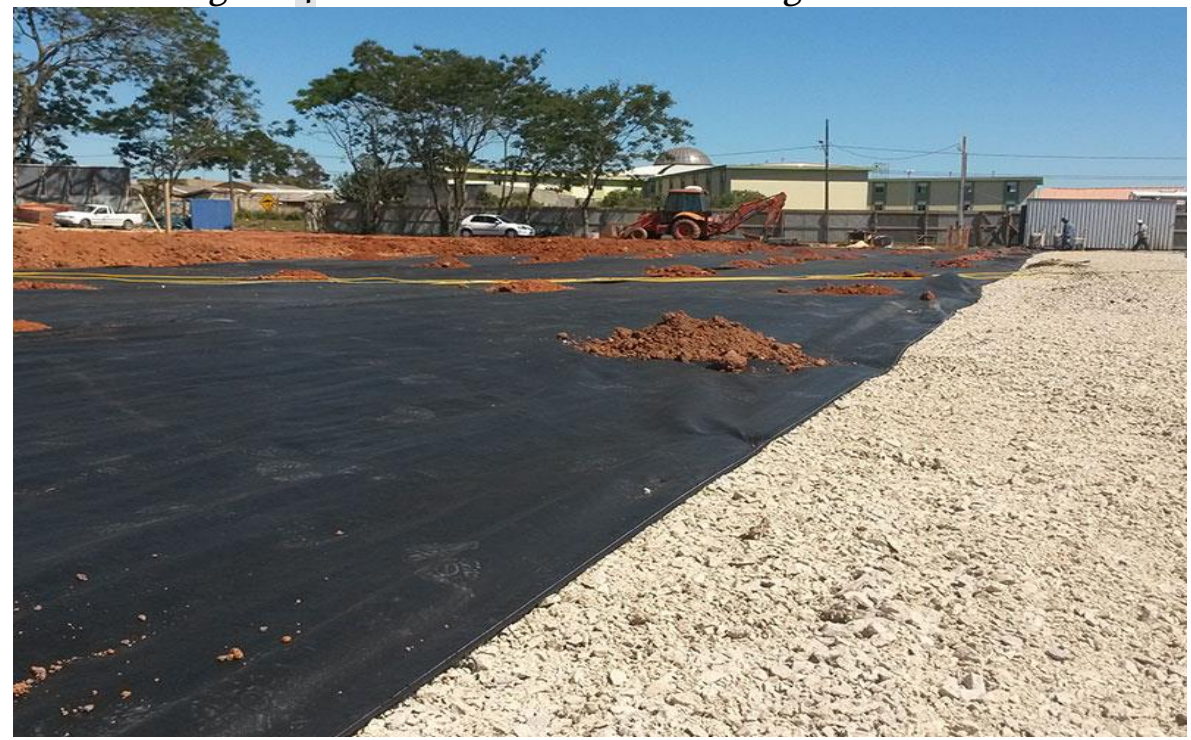

Fonte: Pavimento Permeável, ABCP (2013)

O Projeto Técnico: Pavimento Permeável da ABCP (2013) recomenda que o 346 lançamento do CPCP seja feito de maneira rápida e contínua sobre a camada de base ou diretamente sobre o subleito, isto é, sobre o solo. No mesmo raciocínio, concordam Lamb et al (2013), que sugerem que o CPCP requer mais cuidados do que o convencional; dentre eles, está o período máximo para conclusão da concretagem de até uma hora, pois há um aumento na taxa de evaporação, o que acarreta a rápida perda de água para o ambiente, afetando a qualidade e a resistência. Para aumentar esse tempo, muitas usinas de concreto têm recorrido ao uso de aditivos retardadores de pega.

Ainda de acordo com o mesmo documento, a ABCP (2013) recomenda que tanto a base como o subleito devem estar úmidos a fim de se evitar a perda de água da pasta de cimento do CPCP. Já para a acomodação do material (ou adensamento), é recomendada a utilização de régua vibratória (figura 5), rolo metálico (figura 6) ou mesmo manualmente com régua de alumínio. De fato, Sandoval et al (2020) também concordam quanto ao uso de rolo metálico. 
Figura 5 - Régua vibratória adensando CPCP

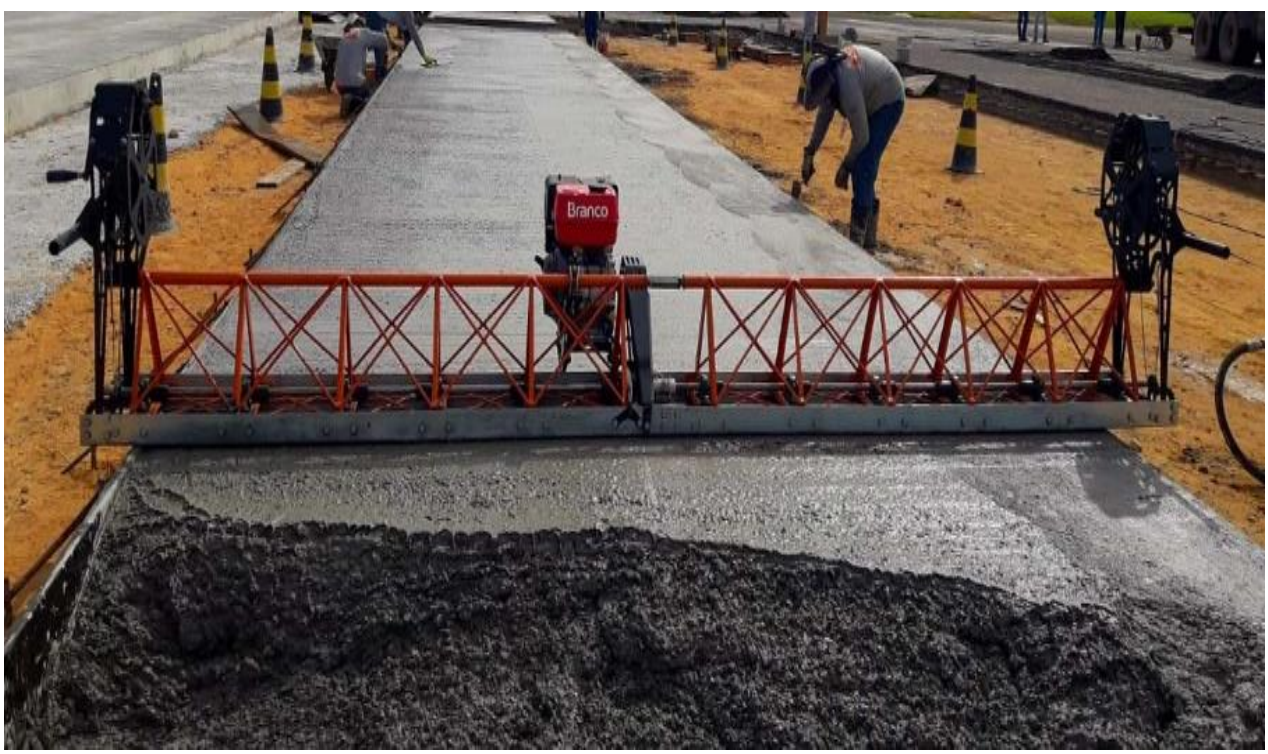

Fonte: Schwetz et al (2015)

Figura 6 - Rolo metálico usado na compactação do CPCP

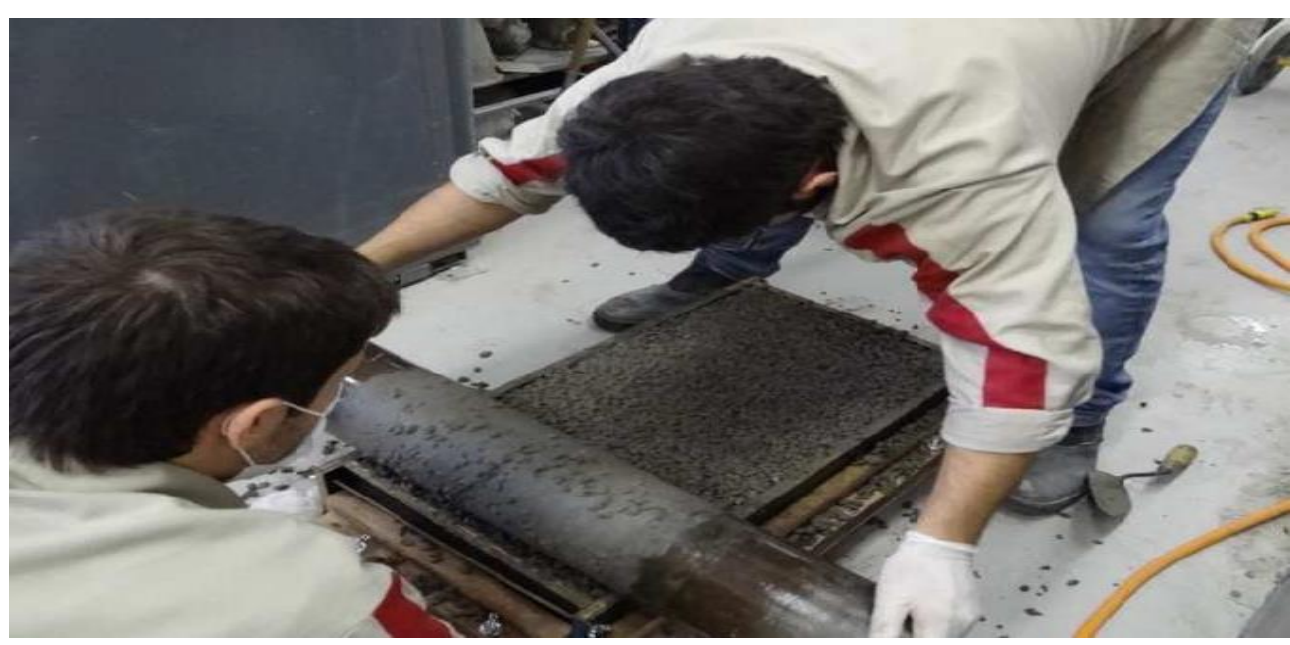

Fonte: Lamb et al (2013)

Entretanto, a ABCP alerta explicitamente que a demora nesse processo pode causar a obstrução dos poros do pavimento. De fato, Joshaghani et al (2015) e Wang et al (2020) afirmam que a energia de compactação deve ser analisada cuidadosamente para evitar diminuição do volume e o comprometimento das propriedades de infiltração, já que esse processo atua diretamente na distribuição da pasta de cimento sobre os agregados graúdos, influenciando as características de porosidade do CPCP. 
Tantos cuidados são explicados por Xie et al (2019) ao afirmarem que a relação cimento/agregado e o procedimento de adensamento do CPCP são os fatores mais importantes na mistura, pois influenciam diretamente nas características mecânicas e afetam, consequentemente, sua funcionalidade no tocante à resistência mecânica e à condutividade hidráulica do pavimento. Além disso, o tempo de transporte e lançamento é encurtado em função da pega do cimento.

Já no tocante à moldagem de corpos de prova (CPs) para ensaios de resistência à compressão, a tabela 3 da ABNT NBR 5738 (2015), para CPs cilíndricos de $10 \mathrm{~cm} \times 20 \mathrm{~cm}$ (diâmetro $x$ altura) orienta que $o$ material deve ser lançado em duas camadas aproximadamente iguais, adensado por uma haste com 12 golpes em cada uma. A haste, por sua vez, deve ser cilíndrica com 1,6 cm de diâmetro, superfície lisa, com comprimento entre 60 e $80 \mathrm{~cm}$. Quando da acomodação, a haste não deve bater no fundo do molde e atravessar $2 \mathrm{~cm}$ da camada anterior. Na última camada, deve ser previsto excesso de material para rasamento (retirado do excesso) com régua metálica ou colher de pedreiro.

Chandrappa et al (2016) levantaram a possibilidade de se executar CPs tanto 348 cilíndricos (figura 7) como em forma de placas (figura 8).

Figura 7 - CPs prismáticos

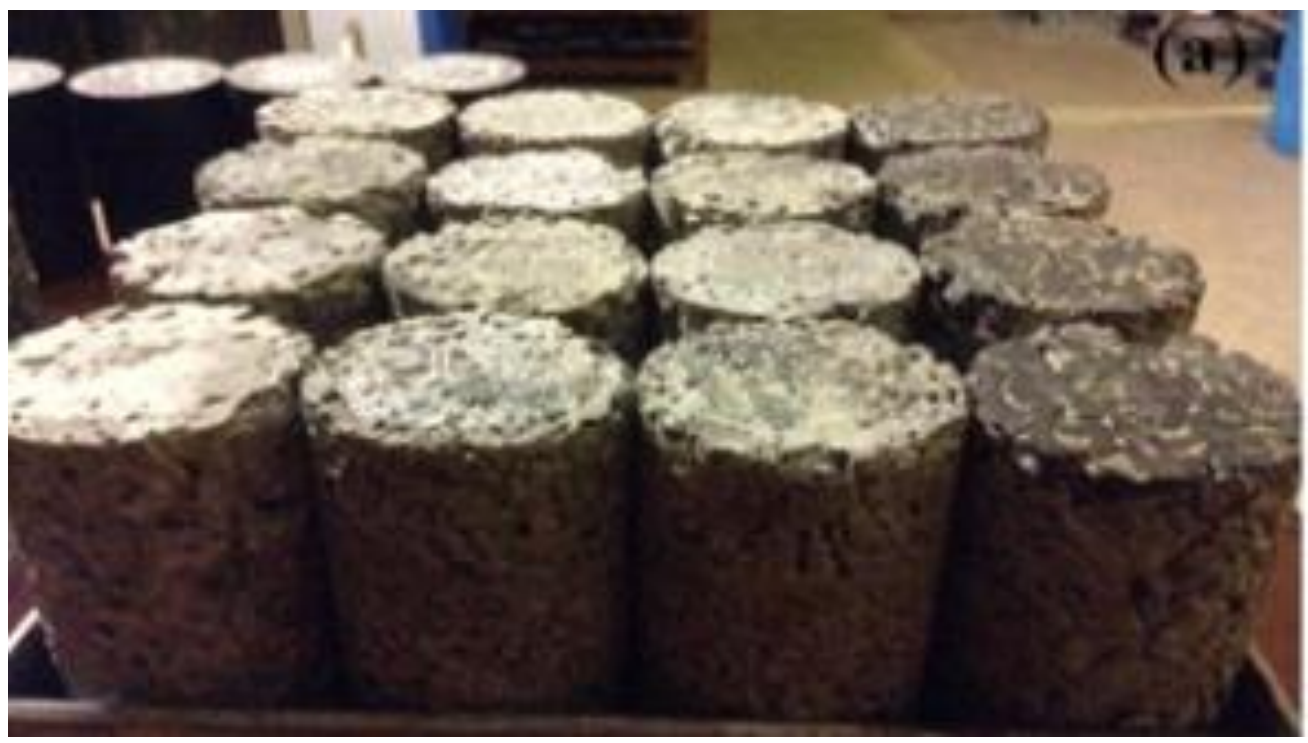

Fonte: Chandrappa et al (2016) 
Figura 8 - CPs em placas

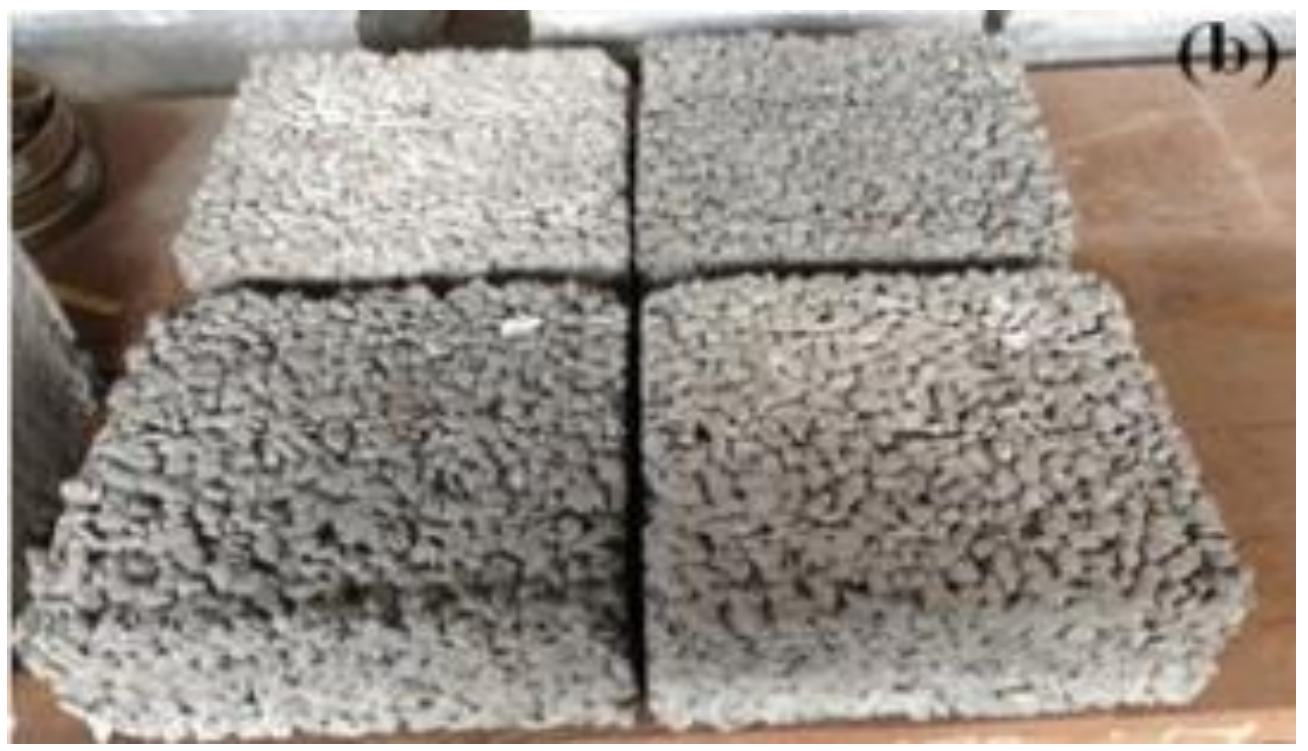

Fonte: Chandrappa et al (2016)

Sandoval et al (2020) recomendam que durante a moldagem de corpos de prova cilíndricos, o CPCP seja compactado com martelo padrão cilíndrico, cujo diâmetro é de $5 \mathrm{~cm}$, altura de $30,5 \mathrm{~cm}$ e massa de $2,50 \mathrm{~kg}$, aplicando-se 10 golpes por camada. Visando mitigar efeitos causados pela variabilidade da aplicação da força no martelo, recomenda-se que seja o mesmo operador a executar esse procedimento. Já para Putman et al (20II), moldar CPs cilíndricos de CPCP usando os mesmos procedimentos recomendados para o concreto convencional, acarreta um resultado impreciso nas propriedades de um pavimento permeável.

\subsubsection{Lona plástica e irrigação na maturação (cura) do Concreto Permeável de Cimento Portland}

Devido à sua estrutura porosa, Kia et al (2017) afirmam que o CPCP necessita de um tempo maior de maturação, processo conhecido como cura e que consiste em impedir a perda prematura de água da pasta de cimento, responsáveis pela reação de hidratação. Para Tibbetts et al (2020), a cura pode influenciar diretamente na permeabilidade do CPCP, que é uma indicadora da durabilidade desse material. 
A $\mathrm{ABCP}$ (2013) recomenda que a cura, isto é, a maturação do CPCP, seja feita com a aplicação de uma lona plástica assim que termine a execução das juntas de dilatação, quando previstas, ou o espalhamento e adensamento do material, com o intuito de impedir a evaporação da água. Xie et al (2019) vão de encontro à ABCP quando recomendam que a cura seja iniciada tão logo termine a concretagem cobrindo o pavimento com uma lona plástica molhada. As pesquisas de Sandoval et al (2020) mostraram ser eficaz um processo de cura que consiste na irrigação do CPCP por 7 dias consecutivos, também não dispensando o uso de lonas plásticas molhadas.

Indo mais além, os estudos de Schwetz et al (2015) se concentraram também em verificar como a cura afeta as propriedades do CPCP. Depois de analisarem três maneiras distintas, concluíram que a cura com manta geotêxtil ou imersa não influenciam nas propriedades do material, além de ser mais onerosas e de difícil execução, ao passo que a cura sob temperatura e umidade ambientes apresentou os melhores resultados para a permeabilidade, a resistência à abrasão e a resistência à compressão. De fato, esses estudos respaldam as recomendações dadas outrora pela ABCP (2013).

\subsubsection{Alguns métodos para determinação da Permeabilidade do Concreto Permeável de Cimento Portland}

Segundo Martins Filho et al (2020), a utilização do CPCP em áreas urbanas minimiza os impactos que são provocados pela pavimentação convencional, ou seja, de concreto impermeável: durante as épocas de chuvas intensas, o mesmo causa inundações repentinas. A permeabilidade é uma propriedade intrínseca do CPCP que permite a passagem de um fluido por meio de sua matriz. Essa característica é atribuída ao fato de possuir uma rede de poros interconectados que formam canais permitindo a drenagem da água por percolação (figura 9). 
Figura 9 - Água percolando amostra de CPCP

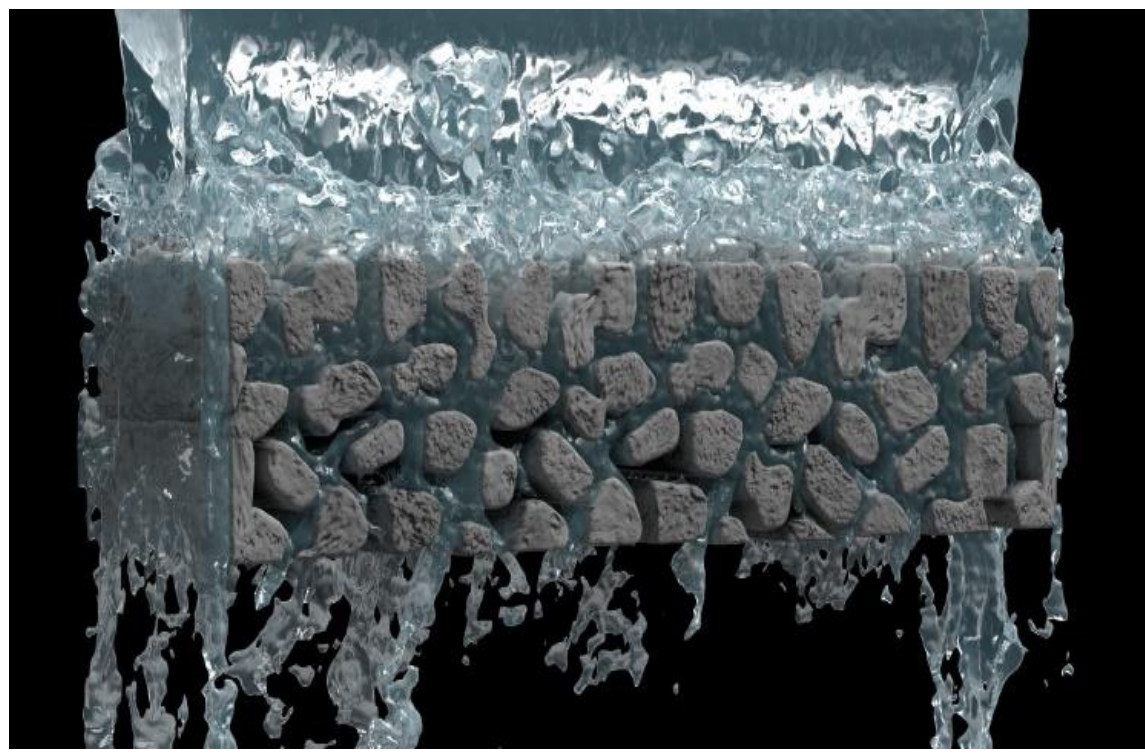

Fonte: Adaptado de Salomão et al (2019)

Concordam Xie et al (2019) ao afirmarem que a condutividade hidráulica do concreto permeável é sua função essencial. Para Li et al (2016), o traço pode afetar consideravelmente

a permeabilidade do concreto, de modo que a quantidade de pasta de cimento seja somente a necessária para envolver a brita. Sandoval et al (2020) constataram que a permeabilidade do CPCP está associada à sua porosidade, ao agregado graúdo e à proporção da pasta de cimento.

De acordo com Sartipi et al (2019), os poros medem entre i e io $\mathrm{mm}$; discordam, todavia, Zhong et al (2018) e Elango et al (2020) que indicaram valores mais precisos entre 2 e $8 \mathrm{~mm}$. Para Zhong et al (2016), a porosidade do CPCP deve ser vista como dois sistemas distintos: a porosidade efetiva, que se caracteriza pelos poros conectados que permitem a percolação de fluido e corresponde à razão entre o volume dessa rede de vazios e o volume total da amostra; e a porosidade total, que compreende os poros isolados e os conectados. A capacidade de permitir que a água infiltre nesse material é extremamente eficaz para controlar inundações.

As pesquisas de El-Dieb et al (1995) demonstraram que a permeabilidade é umas características que definem a durabilidade do CPCP. A partir daí, houve um interesse cada vez maior para se determinar esse parâmetro. 
Tibbetts et al (2020) estudaram os testes de permeabilidade através da passagem de um potencial elétrico e de uma carga elétrica sobre CPs de CPCP, que vêm sendo realizados pela American Society for Testing and Materials (ASTM) desde 1980. Entretanto, os mesmos autores salientam que este método é alvo de críticas por não apresentar resultados fidedignos e por ser uma medição indireta e demorada. Segundo eles, os métodos com fluxo de água sob pressão vêm sendo estudados desde 190o, aproximadamente.

Autores como Neithalath et al (2010) sugerem o ensaio com permeâmetro de carga variável, cujo esquema é ilustrado na figura io.

Quebra de Página

Figura Io - Permeâmetro de carga variável

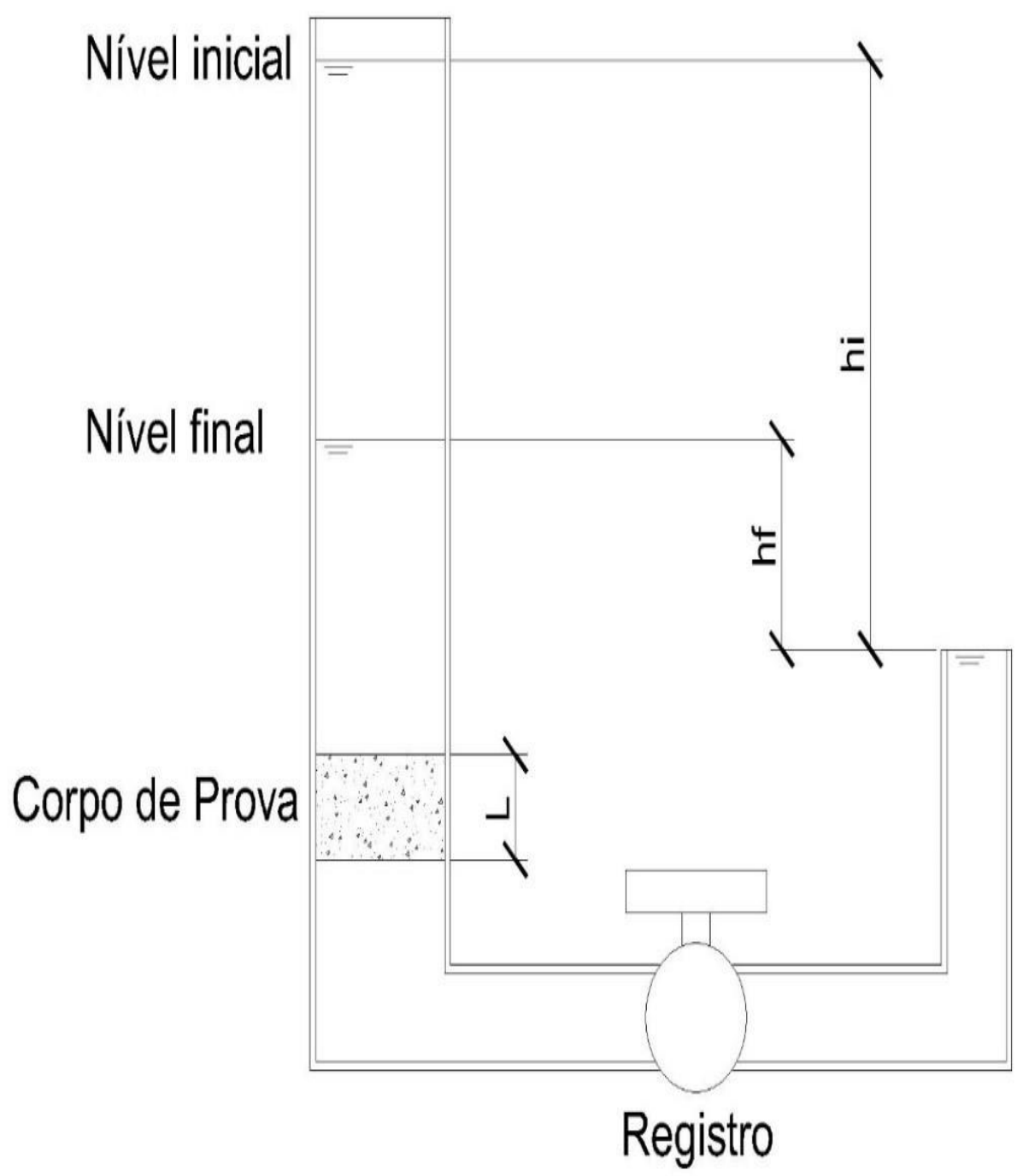


Fonte: Adaptado de Mikami et al (2018)

Mikami et al (2018) e Costa et al (2019) apresentam a equação i para esse ensaio: $\mathrm{K}=\left[\left(\mathrm{A}_{\mathrm{I}} * \mathrm{~L}\right) /\left(\mathrm{A}_{2} * \mathrm{t}\right)\right] * \ln (\mathrm{hi} / \mathrm{hf})$

Onde: K: coeficiente de permeabilidade da água $(\mathrm{m} / \mathrm{s})$;

$\mathrm{A}_{\mathrm{r}}$ : área da seção transversal do $\mathrm{CP}\left(\mathrm{m}^{2}\right)$;

$\mathrm{A}_{2}$ : área da seção transversal da seção transversal da coluna de água $\left(\mathrm{m}^{2}\right)$;

L: altura do CP (m);

hi: nível inicial da água em relação ao extravasor;

hf: nível final em relação ao extravasor;

t: tempo para que a coluna de água baixe do nível inicial ao final (s).

Já para Pierelisi et al (2017), o ensaio de permeabilidade com carga constante é capaz de determinar essa propriedade no caso do CPCP, por apresentar alta porosidade. Ludirdja et al (1989) sugerem que a lei de Darcy é satisfatória para se calcular o coeficiente de permeabilidade, supondo escoamento laminar em meio poroso saturado de água. Para tanto, utiliza-se a equação 2:

$\mathrm{K}=(\mathrm{Q} * \mathrm{~L}) /(\mathrm{A} * \mathrm{P})$

Sendo K: coeficiente de permeabilidade da água $(\mathrm{m} / \mathrm{s})$;

Q: vazão que percola a amostra $\left(\mathrm{m}^{3} / \mathrm{s}\right)$;

L: espessura do CP (m);

A: área da seção transversal da amostra $\left(\mathrm{m}^{2}\right)$;

P: carga hidrostática constante no permeâmetro $(\mathrm{m})$.

Contudo, Zhong et al (2018) alertam que essa equação pode ser controversa quando aplicada à determinação da permeabilidade do CPCP. Os estudos de Huang et al (2010) demonstraram que a Lei de Darcy pode não ser aplicável a materiais que apresentem alta porosidade. Li et al (2016) observam que esses testes em laboratório apresentam a dificuldade na vedação completa do equipamento que pode comprometer os resultados, concluindo que não há técnicas amplamente aceitas para determinar a permeabilidade do CPCP.

Já a ABNT NBR I6416 (2015) sugere um ensaio onde determinado volume de água, determinado em função do tempo de pré-molhagem do pavimento, é despejado sobre um 
anel de $30 \mathrm{~cm}$ de diâmetro, marcado em i e $1,5 \mathrm{~cm}$ (figura II), onde o nível de água deve estar compreendido enquanto esta é despejada durante o ensaio.

Figura II - Anéis utilizados no ensaio recomendado pela ABNT NBR i64I6:2015

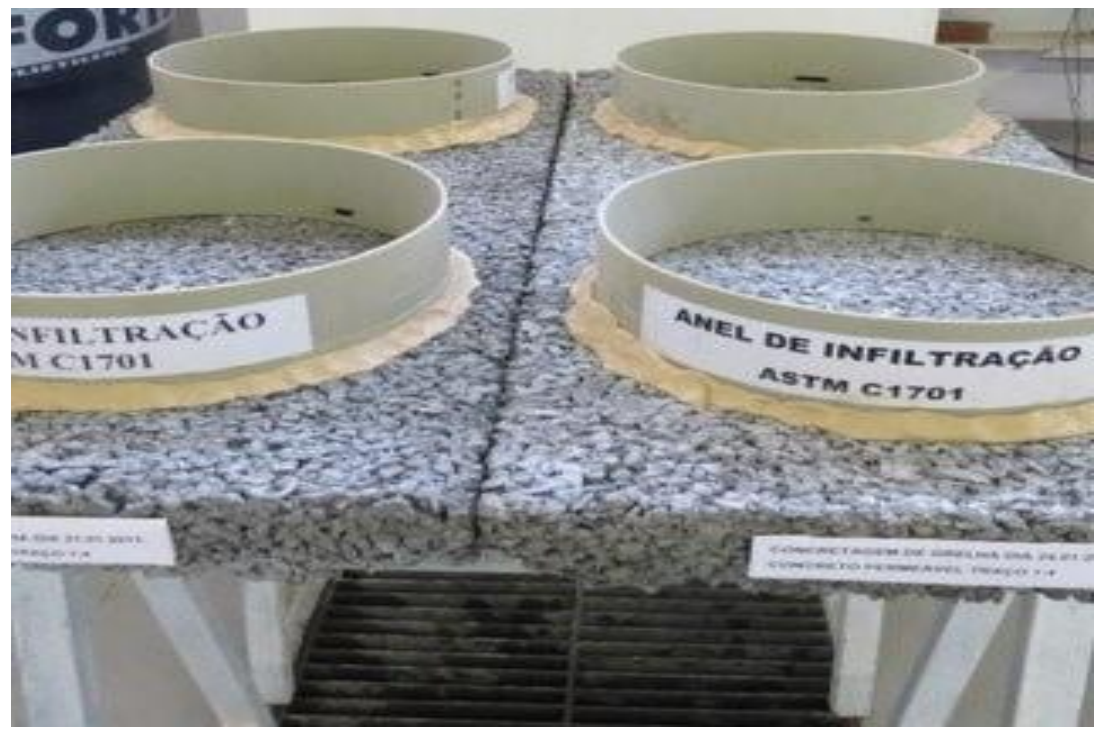

Fonte: Lamb et al (2013)

Se o tempo de molhagem for inferior a $30 \mathrm{~s}$, a amostra de água será $18+$ /- o,05 kg; se maior que $30 \mathrm{~s}, 3,60+/-0,05 \mathrm{~kg}$. O tempo para infiltração total é cronometrado e aplicam-se os dados na equação 3:

$\mathrm{K}=(\mathrm{C} * \mathrm{~m}) /\left(\mathrm{d}^{2 *} \mathrm{t}\right)$

Onde: $\mathrm{K}$ : coeficiente de permeabilidade da água $(\mathrm{mm} / \mathrm{h})$;

C: fator de conversão das unidades do Sistema Internacional e que vale 4.583.666.ooo;

$\mathrm{m}$ : massa da água utilizada no ensaio $(\mathrm{kg})$;

d: diâmetro do anel de infiltração (mm);

t: tempo total para que toda amostra de água infiltre no pavimento (s).

A referida norma proíbe que o ensaio seja realizado antes de passadas $24 \mathrm{~h}$ da última chuva, além de restringir a dois ensaios por dia.

Porém, El-Dieb et al (1995) afirmam que os métodos com carga podem apresentar certa variação nos resultados, o que inspira cuidados para se chegar em valores precisos e corretos. Para Tibbetts et al (2020), a maior vantagem desse tipo de ensaio é a medição direta. Xie et al (2019) alertam que estudos realizados anteriormente com vários métodos de ensaio detectaram que a permeabilidade medida poderia ser cerca de Io\% da real, apontando 
uma necessidade de reavaliar os resultados. Dito isso, alguns autores recomendam a análise numérica da permeabilidade a partir de modelos computacionais mais eficazes.

Li et al (2016) acreditam que o avanço da tecnologia pode ajudar na determinação da permeabilidade do CPCP, citando pesquisas onde foi desenvolvida uma rede bidimensional (2D) para análise dessa capacidade do material; os pesquisadores consideraram como condutoras as três camadas distintas do CPCP (o agregado graúdo, a pasta de cimento e a zona de transição entre pasta e agregado) a fim de verificar a permeabilidade em CPs. Apesar de a maioria dos modelos serem bidimensionais, os autores também citam pesquisas que se valeram de modelos tridimensionais $(3 \mathrm{D})$ mais precisos para estudar as variáveis envolvidas.

Yu et al (2019) relatam em seus estudos que os CPs passaram por uma tomografia computadorizada que gerou 500 fotografias espaçadas cerca de $0,2 \mathrm{~mm}$ ao longo da altura do CP; cada uma dessas imagens pode ser analisada separadamente pelo software Image-pro que apresenta informações como características da estrutura porosa e ainda o tamanho dos poros. O programa Avizo foi utilizado pelos autores para a reconstrução do modelo tridimensional, conforme vê-se na figura 12.

Figura 12 - Análise ${ }_{3} \mathrm{D}$ para simulação da permeabilidade

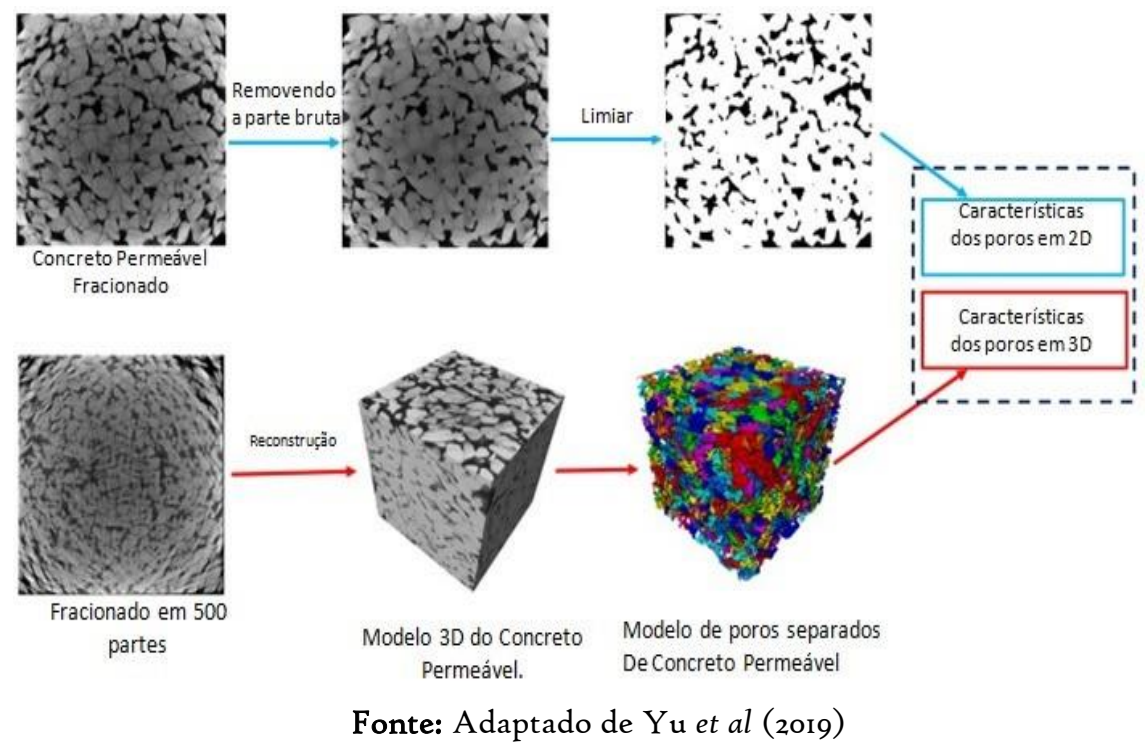


Yu et al (2019) citam a possibilidade de analisar o CP com os poros conectados, que remete à porosidade efetiva. A partir daí, o software é capaz de simular a infiltração de água e determinar a permeabilidade da amostra de CPCP.

Segundo Sandoval et al (2019), em termos hidráulicos, o coeficiente de permeabilidade do CPCP varia de $\mathrm{I}$ a $20 \mathrm{~mm} / \mathrm{s}$, o que assegura o fluxo repentino da água por sua estrutura. Diferentemente das propriedades mecânicas como compressão e flexão, as propriedades hidráulicas cumprem segundo a norma nacional e internacional que estabelecem permeabilidade acima de $\mathrm{I} \mathrm{mm} / \mathrm{s}$.

Além disso, Araújo et al (2000) ressaltam que o solo que receberá o pavimento permeável deve ter capacidade de infiltração superior a $0,002 \mathrm{~mm} / \mathrm{s}$, que pode ser determinada com uma investigação do subsolo em um nível entre 60 e $120 \mathrm{~cm}$ abaixo do reservatório. Para os mesmos autores, as águas penetram no pavimento, que as encaminha rapidamente para um filtro de brita, chegando finalmente a um reservatório de graduação granulométrica mais alta (figura 13), cujas dimensões são determinadas a partir da intensidade pluviométrica da região e da área de contribuição que direciona as águas pluviais para o pavimento permeável.

Figura 13 - Camadas do pavimento

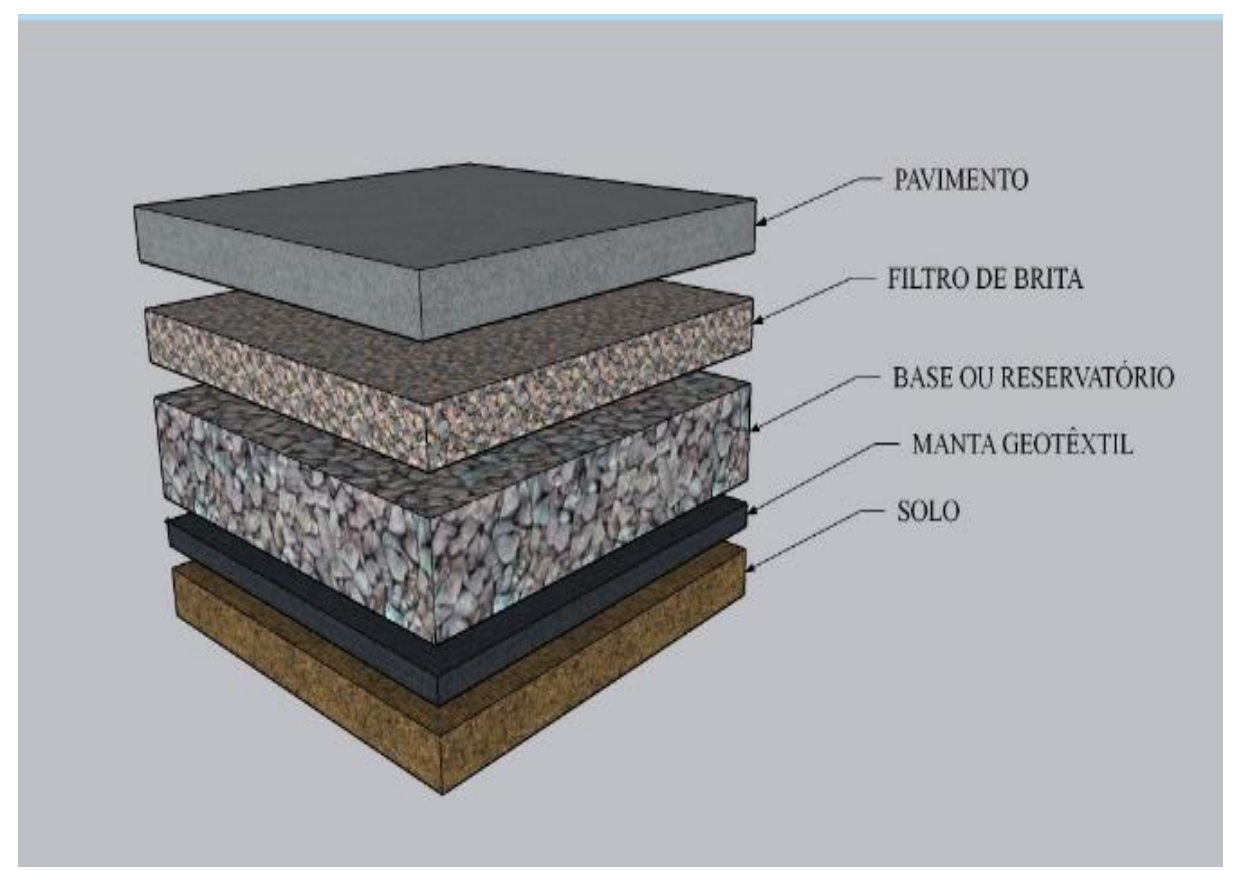

Fonte: Adaptado de Projeto Técnico: Pavimento Permeável (2013) 
Porém, Haselbach et al (2006) apontam para o fato de que mesmo que o solo apresente capacidade de infiltração menor que a do CPCP, o pavimento pode funcionar como reservatório das águas pluviais até que o sistema todo esteja saturado.

Xie et al (2019) observam que pesquisas anteriores comprovaram a eficiência do CPCP na remoção das impurezas de águas pluviais, tais como metais pesados e fluidos automotivos, para pavimentos de $20 \mathrm{~cm}$ de espessura e assentados sobre um filtro de brita e um reservatório. Entretanto, ressaltam que outrora foi registrado um aumento de cloreto nas águas subterrâneas sob o pavimento permeável de um estacionamento em New Jersey.

Zhang et al (2018) realizaram estudos onde se comprovou a remoção de metais pesados a longo prazo, se valendo de testes de I ano que simularam um período de 26 anos de uso do pavimento.

\subsubsection{Relação da resistência à compressão do Concreto Permeável de Cimento Portland com a porosidade $\mathrm{e}$ agregado graúdo}

Conforme Sandoval et al (2019), em termos de resistência mecânica, o CPCP trabalha por volta de 3 a $30 \mathrm{MPa}$, podendo ser utilizado em calçadas de pedestres e vias de tráfego leve. Os mesmos autores relatam que na fabricação desse concreto estão sendo implementados o uso de resíduos de construção civil como agregados, onde as propriedades mecânicas alcançadas com alguns destes agregados variam de 6 a $14 \mathrm{MPa}$ na compressão e I a 2 MPa na flexão, ocorrendo uma redução nessas propriedades relacionadas ao concreto convencional.

Já para Lamb et al (2013), a resistência à compressão do CPCP está na faixa de 3,50 a $28 \mathrm{MPa}$, sendo inferior à do concreto convencional em função da sua alta porosidade, e, por isso, mais utilizado em locais de tráfego leve; enquanto Elango et al (2020) sugerem que essa faixa esteja compreendida entre 2,8 e $28 \mathrm{MPa}$.

Huang et al (2010), entre outros autores, afirmam que a baixa resistência mecânica se deve principalmente à alta porosidade do material. Para eles, essa característica limita o uso do CPCP a pavimentos de tráfego leve ou de pedestres, podendo ser utilizado no máximo em acostamentos de estradas rodoviárias, além de influenciar na durabilidade e na estabilidade dessas estruturas. Para Joshaghani et al (2015), esta é uma desvantagem do uso 
do CPCP, a quando comparado ao concreto convencional. Para contornar tal deficiência, os mesmos autores sugerem aumentar a área de contato da pasta de cimento (figura I4) utilizando agregados graúdos menores, como pedrisco.

Figura I4 - Área de contato entre os agregados graúdos e a pasta de cimento

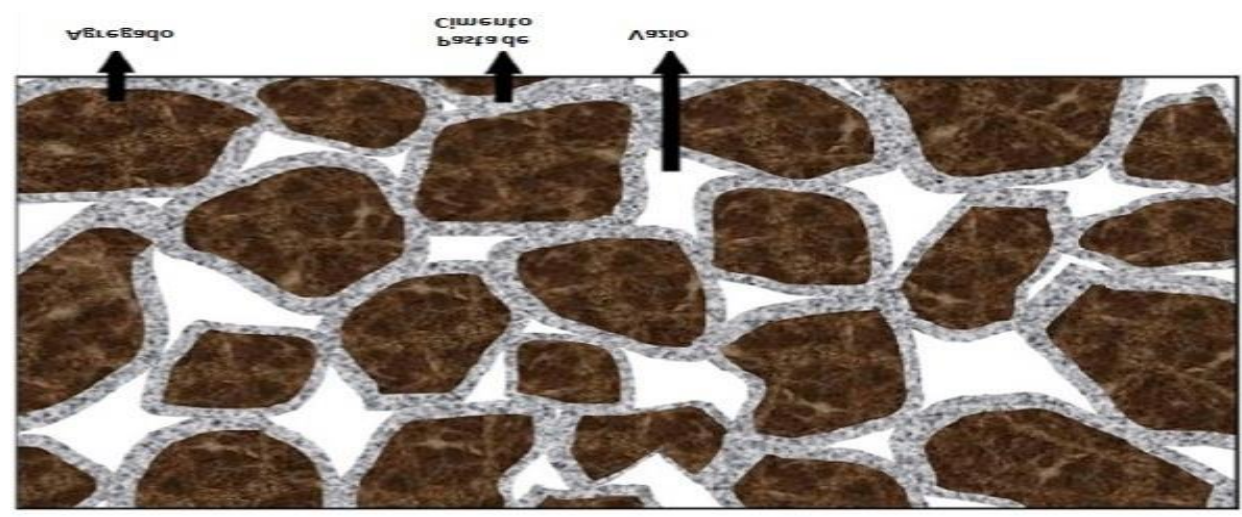

Fonte: Adaptado de Xie et al (2020)

Neste sentido, Zhong et al (2016) concluíram que, via de regra, o aumento do diâmetro do agregado graúdo implica no decréscimo de resistência mecânica, apontando ainda outros autores que corroboram com essa afirmação.

Para Lian et al (2010), a resistência mecânica desse material é melhorada quando se utilizam agregados com graduação entre $2,40 \mathrm{~mm}$ e $9,50 \mathrm{~mm}$, que justamente corresponde à graduação da brita o. Eles também constataram que o aumento no fator a/c implica no decréscimo de resistência (figura is).

Figura 15 - Resistência à compressão em função do fator a/c

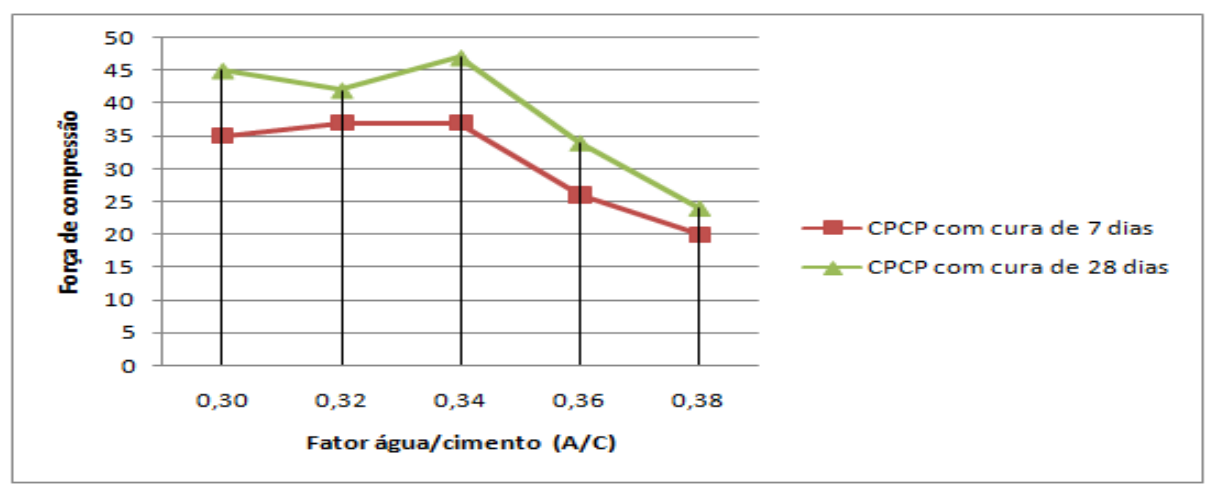

Fonte: Adaptado de Lian et al (2010) 
Os estudos de Maguesvari et al (2013) apontaram que o aumento do volume de agregados miúdos interfere diretamente na permeabilidade do pavimento, porém, acarretam o aumento da resistência à compressão. Elango et al (2020) observaram que agregados de formato irregular apresentaram melhor adesão à pasta de cimento, o que aumentou a resistência mecânica do CPCP; ao passo que agregados com menores diâmetros favorecem a resistência em detrimento da permeabilidade.

Todavia, Kevern et al (2010) discordam que o uso de um agregado graúdo de diâmetro único contribua para se obter um equilíbrio entre permeabilidade e resistência, simultaneamente. As conclusões de Kia et al (2018) revelaram que a resistência à compressão do CPCP diminui $4 \%$ a cada ponto percentual da porosidade, ou seja, essas são grandezas inversamente proporcionais.

Zhong et al (2016) apresentaram estudos em que a resistência à compressão está associada à porosidade do CPCP: pavimentos com porosidade entre 15 e 30\% apresentaram resistência de 7 a $25 \mathrm{MPa}$. Já pavimentos com porosidade fora desses limites ou com tratamento especial, ou seja, com adição de materiais diferentes dos convencionais, não foram testados. Eles concluíram que pavimentos com maior porosidade apresentam menor resistência mecânica, já que a área de contato com a pasta e outros agregados ao redor é reduzida.

\subsubsection{Estudos sobre manutenção e durabilidade do Concreto Permeável de Cimento Portland}

Apesar dos benefícios conhecidos, Xie et al (2019) ressaltam que alguns aspectos podem comprometer a vida útil e a durabilidade do pavimento drenante, dentre os quais pode-se citar o fenômeno chamado de clogging, que consiste no entupimento dos poros do concreto permeável.

Haselbach et al (2006) definem como entupimento o evento onde ocorre o acúmulo parcial ou total de sedimentos nos poros do CPCP e a consequente perda de permeabilidade do pavimento (figura 16 ). 
Figura 16 - Entupimento observado em CPs
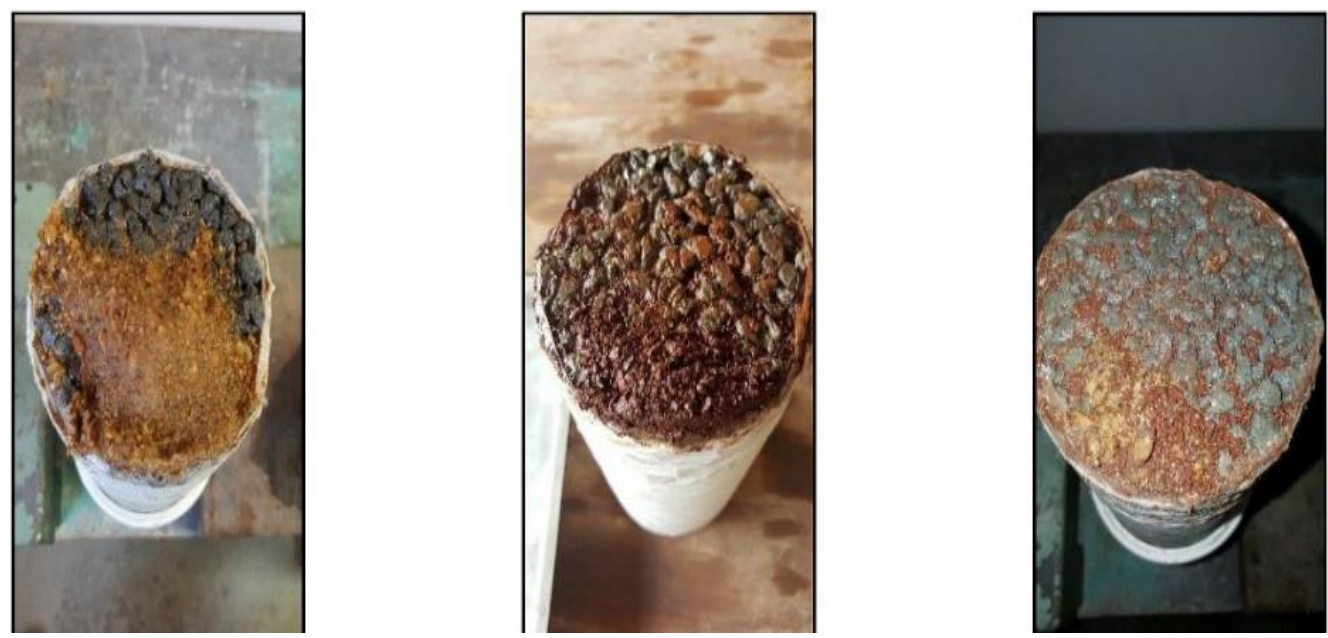

Fonte: Sandoval et al (2020)

Para Kia et al (2017), ao passo que partículas sólidas vão se depositando nos vazios existentes, a porosidade efetiva vai diminuindo, reduzindo a capacidade de infiltração e afetando diretamente a funcionalidade e a durabilidade do material com o passar dos anos. Nguyen et al (2017) concluíram que a argila e a areia siltosa têm maior potencial em entupir os poros do material em menos tempo.

Unissonante, Sandoval et al (2020) afirmam que a quantidade de poros favorece esse evento. Segundo os autores, as pequenas dimensões das partículas de solo e areia facilitam o transporte durante as chuvas. Lin et al (2016) mostraram que o pavimento permeável perde cerca de $54 \%$ de sua capacidade de permeabilidade ao longo do tempo; apontaram também que, em geral, a manutenção deve ser feita após 2 anos de uso.

Balades et al (1995) sugeriram que a colmatação acontece apenas na camada superficial do pavimento e, após testarem quatro diferentes métodos para descolmatação do CPCP como varrimento simples (Figura 17a) após umedecimento do local, varrimento com aspiração (Figura $17 \mathrm{~b}$ ), aspiração e jateamento de água sob alta pressão (Figura $17 \mathrm{c}$ ), concluíram que a aspiração ou o jato de água de alta pressão são os métodos mais eficientes e que podem recuperar até 100\% da permeabilidade original do concreto. Por outro lado, Xie et al (2019) apontam estudos que comprovaram que a aspiração do pavimento recuperou cerca de $90 \%$ de sua permeabilidade inicial. 
Figura 17 - Métodos de limpeza mais utilizados do CPCP

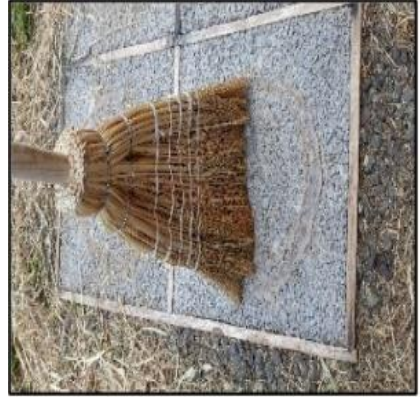

a)

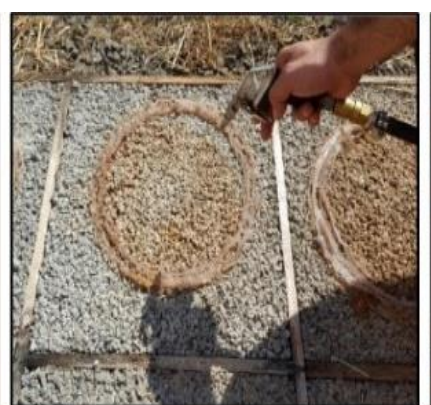

b)

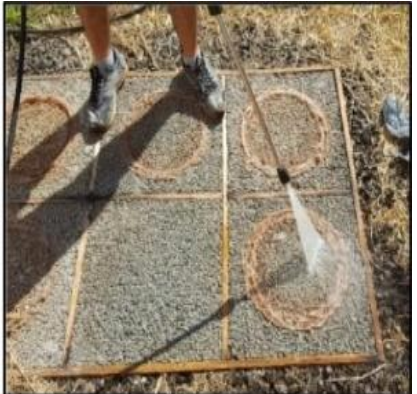

c)

Fonte: Sandoval et al (2020)

A ABNT NBR ı6416 (2015) também recomenda que a descolmatação seja feita por meio de varrição, jateamento de água sob pressão ou utilizando equipamentos de sucção, além de excluir o uso de produtos químicos ou águas contaminadas. Ainda segundo Xie et al (2019), o varrimento com aspiração se mostrou ineficaz em pavimentos com um grau de entupimento nas camadas mais profundas do CPCP.

Entretanto, Sandoval et al (2020) ressaltam que ainda não há uma maneira de se avaliar o entupimento dos poros, de modo que estudos anteriores se encarregaram de adaptar ensaios de permeabilidade adicionando sedimentos como areia e argila (pois podem mais facilmente causar esse fenômeno) e medir a variação da capacidade de infiltração do CPCP, apesar de esse método ainda não ser preciso e a confiabilidade dos resultados não ser satisfatória. As pesquisas dos mesmos autores mostraram que equações exponenciais empíricas foram propostas relacionando a variação da permeabilidade e a massa de sedimentos, mas não foram validadas.

Entretanto, Haselbach et al (2006) apontam que é difícil simular um pavimento permeável totalmente entupido, já que seria quase impossível fechar todos os poros do CPCP, além de ser um tanto improvável que um sistema apresente tal situação. Porém, esses autores acreditam que seria capaz simular esse parâmetro colocando uma camada de areia fina de cerca de $5 \mathrm{~cm}$ sobre o pavimento.

Os estudos de Kumar et al (2016) constataram que mesmo após dois anos de uso e tendo sido observada uma diminuição significativa da permeabilidade de um pavimento permeável em Illinois, EUA, a capacidade de infiltração do mesmo ainda era maior que a intensidade pluviométrica da região. Xie et al (2019) afirmam que estudos 
comprovaram a eficiência do concreto permeável por 20 ou 30 anos conservando características estruturais semelhantes aos passeios públicos convencionais.

\section{REFERÊNCIAS}

ARAúJO, P. R.; TUCCI, C. E. M.; GOLDENFUM, J. A. Avaliação da eficiência dos pavimentos permeáveis na redução de escoamento superficial. Instituto de Pesquisas Hidráulicas da UFRGS. Porto Alegre, 2000. Disponível em: 〈https://www.researchgate.net/profile/Joel-

Goldenfum/publication/237471602_AVALIACAO_DA_EFICIENCIA_DOS_PAVIMEN TOS_PERMEAVEIS_NA_REDUCAO_DE_ESCOAMENTO_SUPERFICIAL/links/55 913Ifeo8aeierfobaesadf/AVALIACAO-DA-EFICIENCIA-DOS-PAVIMENTOSPERMEAVEIS-NA-REDUCAO-DE-ESCOAMENTO-SUPERFICIAL.pdf $>$. Acesso em: Io mar. 2021.

APPALANAIDU, K.; GUPTA, M. R. V. S.; SHANMUKESH, D. V. Storm water runoff management by using pervious pavement. Alochana Chakra Journal.

Vol. o9, n. 04, p. 5406-54II, abr. 2020. Disponível em: 〈https://www.academia.edu/43743740/STORM_WATER_RUNOFF_MANAGEMENT _BY_USING_PERVIOUS_PAVEMENT>. Acesso em: 23 fev. 2021.

ASADI, S; MARWA, M. H.; KEVERN, J. T.; RUPNOW, T. D. Development of Photocatalytic Pervious Concrete Pavement for

Air and Storm Water Improvements. Transportation Research Record. Vol. 2290, n. or, p. I6I-167, 2012. Disponível em: 〈https://journals.sagepub.com/doi/pdf/ro.314I/2290-2I〉. Acesso em: o9 mar. 2021.

ASSOCIAÇÃO BRASILEIRA DE CIMENTO PORTLAND. Projeto Técnico: Pavimento Permeável. São Paulo, 2013.

ASSOCIAÇÃO BRASILEIRA DE NORMAS TÉCNICAS. NBR 16416:2015: Pavimentos Permeáveis de Concreto - requisitos e procedimentos. Rio de Janeiro, 2015.

ASSOCIAÇÃO BRASILEIRA DE NORMAS TÉCNICAS. NBR 16889:2020: Concreto - determinação da consistência pelo abatimento do tronco de cone. Rio de Janeiro, 2020. 
ASSOCIAÇÃO BRASILEIRA DE NORMAS TÉCNICAS. NBR 5738:2015 (versão corrigida em 2016): Concreto - procedimentos para moldagem e cura de corpos de prova. Rio de Janeiro, 2016.

ASSOCIAÇÃO BRASILEIRA DE NORMAS TÉCNICAS. NBR 9781:2013: Peças de concreto para pavimentação - especificação e métodos de ensaio. Rio de Janeiro, 2013.
BALADES,
J.D.;
LEGRET,
M.; MADIEC,

H. Permeable pavements: pollution management tools. Water Science and Technology: a jornal of the International Association on Water Pollution Research, vol 32, edição I, p. 4956, 1995. Disponível em: $<$ https://iwaponline.com/wst/articleabstract/32/I/49/4374/Permeable-pavements-pollution-managementtools? redirectedFrom=PDF $>$. Acesso em: 23 mar. 202I

BECKER, N.; PINHEIRO, I. Potencialidade dos pavimentos permeáveis na melhoria da qualidade da água do escoamento superficial: uma revisão. Revista Brasileira de Gestão Urbana. Curitiba, vol. II, fev. 2019. Disponível em: <https://www.scielo.br/scielo.php?script=sci_arttext\&pid=S2175$33692019000100221 \& t \operatorname{lng}=p t>$. Acesso em: 23 fev. 2021.

CAldeirA, A.C. V.; SERRADIlha, V.H.; CRUZ, A. H. G.; AlVEZ, L. G.; YOKOMIZO, L. G. P.; RODRIGUES, P. S. H. Estudo e desenvolvimento de concreto permeável com função estrutural e análise de viabilidade de utilização. Revista Engenharia em Ação UniToledo. Araçatuba, vol. oI, n. oI, p. I30-I4I, out./dez. 2016.

CHANDRAPPA, A. K.; BILIGIRI, K. P. Pervious concrete as a sustainable pavement material - Research findings and future prospects: A state-of-theart review. Construction and Building Materials. Vol. III, n. 15, p. 262-274, mai. 2016. Disponível em: <https://www.sciencedirect.com/science/article/pii/So950061816301131?dgcid=raven_sd_re commender_email\#! >. acesso em: 05 jun. 2021.

CHINDAPRASIRT; HATANAKA; CHAREERAT, T.; MISHIMA; YUASA, $Y$. Cement past characteristics and porous concrete properties. Construction and Building Materials. Vol. 22, n. 05, p. 894-901, mai. 2008. Disponível em: 
〈https://www.sciencedirect.com/science/article/pii/So9500618060036r8>. Acesso em: o6 abr. 202I.

CHRISTOFIDIS, D.; ASSUNÇÃO, R.S. F. V.; KLIGERMAN, D. C. A Evolução histórica da Drenagem Urbana: da drenagem tradicional à sintonia com a natureza. Saúde em Debate. Rio de Janeiro, vol. 43, n. 03, dez. 2019. Disponível em: 〈https://www.scielo.br/scielo.php?script=sci_arttext\&pid=So103-11042019000700094〉. Acesso em: 24 fev. 202I.

COSTA, M. C. B.; SILVA, L. S.; NOGUEIRA, M. H. P.; LIMA, G. K. M.; BATISTA, N. J. S. Estudo da viabilidade técnica de concreto permeável em pavimentos urbanos de baixo tráfego utilizando agregado graúdo regional. Revista de Ciência e Tecnologia. Boa Vista, vol. 05, n. 08, 2019.

ELANGO, K. S.; GOPI, R.; SARAVANAKUMAR, R.; RAJESHKUMAR, V.; VIVEK, D.; RAMAN, $\quad$ S. $\quad$ V. Properties of pervious concrete A state of the art review. Materials Today: Proceedings. Versão online, dez. 2020. Disponível em: 〈https://www.researchgate.net/publication/347528267_Properties_of_pervious_concrete__A_state_of_the_art_review>. Acesso em: 23 abr. 2021.

EL-DIEB, A.S.; HOOTON, R. D. Water permeability measurement of high performance concrete using a highpressure triaxial cell. Cement and Concrete Research. Vol. 25, n. o6, p. I199-I208, ago. 1995. Disponível em: 〈https://www.sciencedirect.com/science/article/pii/ooo88846950oIn2P〉. Acesso em: o6 abr. 202I.

HASELBACH, L. M.; VALAVALA, S.; MONTES, F. Permeability predictions for sandcloogged Portland cement pervious concrete pavement systems. Journal of Environmental Management. Vol. 8I, n. oI, p. 42-49, out. 2006. Disponível em: 〈https://www.sciencedirect.com/science/article/pii/So301479705003270\#!〉.

Acesso em: 07 abr. 2021.

HUANG, B.; WU, H.; SHU, X.; BURDETTE, E. G. Laboratory evaluation of permeability and strenght of polymermodified pervious concrete. Construction and Building Materials. Vol. 24, n. 05, p. 818-823, 
mai. 2010. Disponível em: 〈https://daneshyari.com/en/article/259531 $>$. Acesso em: o9 abr. 2021.

JOSHAGHANI, A.; RAMEZANIANPOUR, A. A.; ATAEI, O.; GOLROO, A. Optimizing pervious concrete pavement mixture design by using the Taguchi method. Construction and Building Materials. Vol. Ior, p. 317-325, dez. 2015. Disponível em: <https://www.sciencedirect.com/science/article/pii/So950061815305158?dgcid=raven_sd_re commender_email>. Acesso em: 06 abr. 2021.

INSTITUTO BRASILEIRO DE GEOGRAFIA E ESTATÍSTICA, Disponível em: www.ibge.gov.br/cidades-e-estados/sp/franciscomorato. Acesso em: 26 ago. 2021 KEVER, J. T.; WANG, K.; SCHAEFER, V. R. Effect of Coarse Aggregate on the FreezeThaw Durability of Pervious Concrete. Journal of Materials in Civil Engeneering. Vol. 22, n. 05, mai. 2010. Disponível em: 〈https://ascelibrary.org/doi/abs/ı.106I/(ASCE)MT.19435533.0000049>. Acesso em: 22 abr. 2021.

KIA, A.; WONG, H. S.; CHEESEMAN, C. R. Clogging em permeable concrete: a review. Journal of Environmental Management. Londres, vol. 193, p. 221-233, mai. 2017.

Disponível em: $\langle$ https://www.sciencedirect.com/science/article/pii/So301479717301226?via\%3Dihub〉. Acesso em: 23 fev. 2021.

KIA, A.; WONG, H. $\quad$ S.; CHEESEMAN, R. Defining clogging potential for permeable concrete. Journal of Environmental Management. Londres, vol. 220, p. 44-53, ago. 2018. Disponível em: 〈https://www.sciencedirect.com/science/article/pii/So301479718305358?dgcid=raven_s d_recommender_email\#bib2r >. Acesso em: 09 abr. 2021.

KUMAR, K.; KOSAK, J.; HUNDAL, L.; COX, A.; ZHANG, H.; GRANTO, T. Insitu infiltration performance of different permeable pavements in a employee used parking lot A four-year study. Journal of Environmental Management. Vol. I67, p. o8-I4, fev. 2016. Disponível em: <https://legacy.mwrd.org/irj/go/km/docs/MWRD_in_the_News/16\%20020IJJournal\%20 of\%2oEnvironmental\%2oManagement_Permeable_Pavement.pdf $>$. Acesso em: I3 abr. 202I. 
LAMB, G. S.; OlIVEIRA, I. A.; PERERA, G.; PASSUELO, A.; LORENZI, A.; SILVA FILHO, L. C. P. Estudo do comportamento de elementos de drenagem confeccionados em concretos permeáveis. In: $55^{\circ}$ Congresso Brasileiro do Concreto

- Ibracon. Anais [...]. Gramado, Out. 2013.

Disponível

em:

〈https://www.researchgate.net/profile/Luiz-Carlos-Silva-

Filho/publication/283796373_Estudo_do_comportamento_de_elementos_de_drenagem_conf eccionados_em_concretos_permeaveis/links/5647aoooo8ae54697fbbe8b6/Estudo-docomportamento-de-elementos-de-drenagem-confeccionados-em-concretospermeaveis.pdf $>$. Acesso em: Io mar. 202I. LI,
$\mathrm{X}$;
XU,
Q.;
CHEN,

S. An experimental and numerical study on water permeability of concrete. Construction and Building Materials. Vol. I05, p. 503-510, fev. 2016. Disponível em: 〈https://www.sciencedirect.com/science/article/pii/So950061815308564〉. Acesso em: o6 abr. 202I.

LIAN, C.; ZHUGE, Y. Optimum mix design of enhanced permeable concrete

- An experimental investigation. Construction and Building Materials. Vol. 24, p.26642671, 2010. Disponível em: <https://reader.elsevier.com/reader/sd/pii/So95006I81ooor789?token=270D8E3E9750oFI86

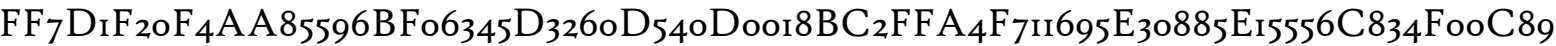
6A6AD>. Acesso em: 19 mar. 2021.

LIN, W.; PARK, D.; RYU S.W.; LEE, B.; CHO, Y. Development of permeability test method for porous concrete block pavement material s considering clogging, Construction and Building Materials. Vol. I18, 2016, Pages 20-26, Disponível em: 〈https://www.sciencedirect.com/science/article/pii/So95006181630407X〉. Acesso em: 23 mar. 2021
LUDIRDJA,
D.;
BERGER,
R.
L.;
YOUNG, $\mathrm{J}$.

F. Simple Method for Measuring Water Permeability of Concrete. Materials Journal. Vol. 86, n. $05, \quad$ p. 433-439, jan. 1989. Disponível em: <https://www.concrete.org/publications/internationalconcreteabstractsportal/m/details/ id/2000>. Acesso em: 05 abr. 2021. 
LUND, M. S. M.; KEVERN, J. T.; SCHAFER, V. R.; HANSEN, K. K. Mix design for improved strength and freeze-thaw durability of pervious concrete fill in Pearl-Chain Bridges. Materials and Structures. Vol. 50, n. oI, p. I-I5, 2017. Disponível em: 〈https://link.springer.com/article/ro.1617/si1527-016-0907-4〉. Acesso em: I2 mar. 2021.

MAGUESVARI, M U.; NARASIMHA,

V.L. Studies on Characterization of Pervious Concrete

for Pavement Applications. Procedia - Social and Behavioral Sciences. Vol.104, p. 198-207, 2013.

Disponível

em:

<https://www.researchgate.net/publication/273851922_Studies_on_Characterization_of_Pe rvious_Concrete_for_Pavement_Applications $>$. Acesso em: I8 mar. 2021.

MARTINS FILHO, S. T.; BOSQUESI, E. M.; FABRO, J. R.; PIERALISI, R. Caracterização do concreto permeável com foco em ensaios não destrutivos. Revista IBRACON de Estruturas e Materiais. São Paulo, vol. 13, n. 03, maio 2020. Acesso em: $<$ https://www.scielo.br/scielo.php?pid=Si983-

41952020000300483\&script=sci_arttext\&tlng=pt >. Acesso em: 23 fev. 2021.

MENEZES FILHO, F. C. M.; AMARAL, D. B. Histórico de expansão urbana e ocorrência de inundações na cidade de Cuiabá-MT. Revista Sociedade \& Natureza. Uberlândia, vol. 26, n. oI, jan./abr. 2014. Disponível em: 〈https://www.scielo.br/scielo.php?script=sci_arttext\&pid=SI982451320140ooroor59\&lng=pt\&nrm=iso $>$. Acesso em: 24 fev. 2021. MIKAMI, R. J.; KRUGER, P.; PEREIRA, E.; KUMMER, A. C. B.; DÖLL, M. M. R. Influência do teor de cerâmica vermelha do agregado reciclado nas propriedades do concreto permeável. Revista Matéria. Vol. 23, n. 03, 2018. Disponível em: 〈https://www.scielo.br/j/rmat/a/yjFNdrqGmMdNCpHbcspRx9Q/?format=pdf\&lang=p t>. Acesso em: 20 mai. 202I.

NEITHALATH, N.; SUMANASOORIYA, M. S.; DEO, O. Characterizing pore volume, sizes, and connectivity in pervious concretes for permeability prediction. Materials Characterization. Vol. 6I, n. o8, p. 802-813, ago. 2010. Disponível em: <https://fdocuments.in/document/characterizing-pore-volume-sizes-andconnectivity-in-pervious-concretes-for.html>. Acesso em: I8 mar. 202I. 
NGUYEN, D. H.; BOUTOUIL, M.; SEBAIBI, N.; BARAUD, F.; LELEYTER, L. Durability of pervious concrete using crushed seashells. Construction and Building Mat erials. Vol. 135, p. I37-I50, mar. 2017. Disponível em: 〈https://www.sciencedirect.com/science/article/pii/So950061816321419〉. Acesso em: o9 abr. 2021.

OKI, T.; KANAE, S.

Global Hydrological Cycles and World Water Resources. Science Journal. Vol. 313, n. 5790, 2006. ago. Disponível em: $\langle$ http://climate.envsci.rutgers.edu/pdf/OkiKanaeGlobalHydrologyı68.pdf $\rangle$. Acesso em: 24 fev. 202I.

PARRA, G. G.; TEIXEIRA, B. A. N. Análise da permeabilidade e dos métodos de instalação de pavimentos permeáveis contidos em artigos científicos e em catálogos técnicos. Revista Nacional de Gerenciamento das Cidades. Vol. 03, n. 15, p. 142-157, 2015. Disponível em: 〈https://amigosdanatureza.org.br/publicacoes/index.php/gerenciamento_de_cidades/ article/view/ıo13>. Acesso em: is mar. 2021.

PIERALISI,

R.;

CAVALARO,

S.H.P.;

AGUADO,

A. Advanced numerical assessment of the permeability of pervious concrete. Cement and Concrete Research. Vol. I02, p. I49-160, dez. 2017. Disponível em: $\langle$ https://www.sciencedirect.com/science/article/pii/Sooo8884617303265〉. Acesso em: I8 mar. 2021.

PILS, S. E.; OliveirA, P.; REGOSO, F.; PAUlON, V. A.; COSTElla, M. F. Concretos drenantes: estudo de dosagem e adição de fibras de polipropileno. Revista IBRACON de Estruturas e Materiais. São Paulo, vol. I2, n. oI, p. IOI-I2I, fev. 20I9. Disponível em: 〈https://www.scielo.br/pdf/riem/vi2nI/pt_I983-4195-riem-I2-or-ooror.pdf 〉. Acesso em: $23 \mathrm{fev} .2021$.

PRATT, C. J.; MANTLE, J. D. G.; SCHOFIELD, P. A. Urban Stormwater Reduction and Quality Improvement through the Use of Permeable Pavements. Water \& Science Technology. Brighton, vol. 21, n. o8-o9, p. 769-778, 1989. Disponível em: <https://iwaponline.com/wst/article/21/8-9/769/23662/UrbanStormwater-Reduction-and-Quality-Improvement>. Acesso em: 02 mar. 202I. 
PUTMAN,

R.

J.;

NEPTUNE,

A.

I. Comparison of test specimen preparation techniques for pervious concrete pavements.

Construction and Building Materials. Vol. 25, ago. 2011, p. 3480-3485. Disponível em: <https://www.researchgate.net/publication/251621645_Comparison_of_test_specimen_prep aration_techniques_for_pervious_concrete_pavements $>$. Acesso em: I9 mai. 2021.

SAlOMÃO, P. E. A.; OlIVEIRA, L. L. S.; RHIS, A. R.; COELHO, S. S. F. Análise e estudos de materiais para aproveitamento de água em pavimento permeável quando comparado ao pavimento convencional. Research, Society and Development. Vol. 8, n. 04, p. e3584912, fev. 2019. Disponível em: 〈https://www.redalyc.org/jatsRepo/5606/560662195035/html/index.html〉. acesso em: os jun. 2021.

SANDOVAL, G.F.B.; CAMPOS, A.; JUSSIANI, E.; TORALLES, B.; CASA NOVA, A.; Proposal of maintenance methodology for pervious concrete (PC) after the phenomenon of clogging. Construction and Building Materials. Volume 248, jul. 2020. Disponível em: 369

< https://www.sciencedirect.com/science/article/pii/So950061820306772?dgcid=raven_sd_ recommender_email> Acesso em 03 jun. 2021.

SANDOVAL, G. F. B.; GALOBARDES, I.; CAMPOS, A.; TORALlES, B. M. Assessing the phenomenon of clogging of pervious concrete

Experimental test and model proposition. Journal of Building Engeneering. Vol. 29, mai. 2020 .

Disponível em: 〈https://www.sciencedirect.com/science/article/pii/S235271021931558X?dgcid=raven_sd_re commender_email> Acesso em: 06 abr. 2021.

SANDOVAL, G. F. B.; GALOBARDES, I.; DIAS, C.; MOURA, A. C.; TORALLES, B. M. Concreto permeável com adição de escória de forno elétrico (FEA): propriedades mecânicas e hidráulicas. Revista IBRACON de Estruturas e Materiais. São Paulo, vol. I2, n. 13, p. 590-607, jun. 2019. Disponível em: 〈https://www.scielo.br/pdf/riem/vi2n3/pt_19834195-riem-12-03-590.pdf >. Acesso em: 23 fev. 2021.

SARTIPI, $\quad$ M.;

SARTIPI,

F. Stormwater retention using pervious concrete pavement: Great Western 
case study. Case Studies in Construction Materials. Vol. II, dez. 2019. Disponível em: <https://www.sciencedirect.com/science/article/pii/S2214509519303766?dgcid=raven_sd_re commender_email $>$. Acesso em: 05 abr. 202I

SCHWETZ, P. F.; SILVA FILHO; L. C. P.; LINHARES V.; LORENZI, A.; FERREIRA, L. Z.; PARISOTO, M. Concreto Permeável: otimização do traço para pavimentação de fluxo leve. In: CONPAT 2015. Lisboa, set. 2015. Disponível em: <https://www.researchgate.net/profile/Alexandre-

Lorenzi/publication/27951322I_Concreto_permeavel_otimizacao_do_traco_para_pavimentac ao_de_fluxo_leve/links/5593f96708ae5af2boecde7a/Concreto-permeavel-otimizacao-dotraco-para-pavimentacao-de-fluxo-leve.pdf $>$. Acesso em: Io mar. 2021.

SIlvA, A. A. P.; SOUZA, G. D. S. C.; RIBEIRO, J. M.; CORDEIRO, L. N. P. Permeability and clogging study of pervious concretes using additives in the Amazon $R$ egion. Brazilian Journal of Development. São José dos Pinhais, vol. 7, n. 01, 2021. Disponível em: 〈https://www.brazilianjournals.com/index.php/BRJD/article/view/23135/18584〉.

Acesso em: 22 mar. de 2021.

SOTO-PÉREZ,

L.; $\quad$ HWANG,

S.

$\operatorname{Mix}$

design and pollution control potential of pervious concrete with non-

compliant waste fly ash. Journal of Environmental Management. Vol. 176, n. or, jul. 2016. Disponível em: 〈https://www.sciencedirect.com/science/article/pii/Sozor479716301049〉. Acesso em: 25 abr. 2021.

TIBbETTS, C. M.; PARIS, J. M.; FERRATO, C.C.; CAVAlgANDO, K. A.; TOWNSEND, $\mathrm{T}$. G. Relating water permeability to electrical resistivity and chloride penetrability of concre te containing different supplementary cementitious materials. Cement and Concrete Com posites. Vol. I07, mar. 2020. Disponível em: 〈https://www.sciencedirect.com/science/article/pii/So958946519313344〉. Acesso em: 3I mar. 202I.

TUCCI, C. E. M. Drenagem Urbana. Ciência e Cultura. São Paulo, vol. 55, n. o4, out./dez. 2003.

Disponível

em: 
$\langle$ http://cienciaecultura.bvs.br/scielo.php?script=sci_arttext\&pid=Sooog67252003000400020>. Acesso em: 24 fev. 202I.

WANG, Z.; ZOU, D.; LIU, T.; ZHOU, A.; SHEN, M. A novel method to predict the mesostructure and performance of pervious concrete. Constru ction and Building Materials. Vol. 263, dez. 2020. Disponível em: 〈https://www.researchgate.net/publication/343019769_A_novel_method_to_predict_the_m esostructure_and_performance_of_pervious_concrete>. Acesso em: 06 abr. 2021.

YANG, J.; JIANG, G.

Experimental study on properties of pervious concrete pavement materials. Cement and C oncrete Research. Vol. 33, n. 03, mar. 2003, p. 381-386. Disponível em: < https://www.sciencedirect.com/science/article/pii/Sooo8884602009663>. Acesso em: 02 mai. 202I.

YU,

F.;

SUN,

D. Study on the pores characteristics and permeability simulation of pervious concrete bas ed on $2 \mathrm{D} / 3 \mathrm{D}$ CT images. Construction and Building Materials. Vol. 200, mar. 2019, p. 687702. em: <https://www.sciencedirect.com/science/article/pii/So950061818331246?dgcid=raven_sd_re commender_email>. Acesso em: or jun. 2021.

XIE, N.; AKIN, M.; SHI, X. Permeable concret pavements: A review of environmental benifits and durability. Journal of Cleaner Production. Vol. 210, p. I605-I621, fev. 2019. Disponível em: 〈https://www.sciencedirect.com/science/article/pii/So959652618335376?dgcid=raven_sd_re commender_email $>$. Acesso em: 13 abr. 2021.

XIE, Xiaogeng; ZHANG, Tongsheng; WANG, Chao; YANG, Yongmin; BOGUSH, Anna; KHAYRULINA, Elena; HUANG, Zhaoming; WEI, Jiangxiong; YU, Qijun. Mixture proportion design of pervious concrete based on the relationships bet ween fundamental properties and skeleton structures. Cement and Concrete Composites. $\begin{array}{llll}\text { Vol. } & \mathrm{II} 3, & \text { out. } & \text { Disponível }\end{array}$ em: <https://reader.elsevier.com/reader/sd/pii/So958946520302006?token=oABC6CE557F 
orF893F $720 \mathrm{Do}_{7} \mathrm{E}_{11} \mathrm{D}_{8} \mathrm{~A}_{3} \mathrm{CFFAFFD}_{37} \mathrm{D}_{7} \mathrm{CE}_{0 .} \mathrm{D}_{2} \mathrm{ED}_{9} \mathrm{C}_{45} \mathrm{BC}_{4} \mathrm{D}_{19} \mathrm{FEB}_{7} \mathrm{C}_{593} \mathrm{EBF}_{9} \mathrm{~F}_{9109} \mathrm{C}$ FFC95A6699BADDi98>. Acesso em: 23 fev. 2021.

ZHANG, K.; YONG, F.; MCCARTHY, D. T.; DELETIC, A. Predicting long term removal of heavy metals from porous pavements for stormwater $t$ reatment. Water Research. Vol. I42, p. 236-245, out. 2018. Disponível em: $\langle$ https://www.researchgate.net/publication/32530478I_Predicting_long_term_removal_of_ heavy_metals_from_porous_pavements_for_stormwater_treatment>. Acesso em: i4 abr. 2021.

ZHONG, R.; LENG, Z.; POON, C. Research and application of pervious concrete as a sustainable pavement material:

A state-of-the-art and state-of-thepractice review. Construction and Building Materials. Vol. I83, set. 2018. Disponível em: 〈https://www.sciencedirect.com/science/article/pii/So950061818315289?dgcid=raven_sd_re commender_email>. Acesso em: 09 abr. 202I.

ZHONG,

WILLE,

$\mathrm{K}$. Compression response of normal and high strength pervious concrete. Construction an d Building Materials. Vol. I09, p. 177-187, abr. 2016. Disponível em: 〈https://www.sciencedirect.com/science/article/pii/So9500618163005I4〉. Acesso em: o9 abr. 202I. 